\title{
Orientation-Tuned Surround Suppression in Mouse Visual Cortex
}

\author{
Matthew W. Self, ${ }^{1 \star}$ Jeannette A.M. Lorteije, ${ }^{1 \star}$ Joris Vangeneugden, ${ }^{1 \star}$ Enny H. van Beest, ${ }^{1}$ Mihaela E. Grigore, ${ }^{1}$ \\ Christiaan N. Levelt, ${ }^{2}$ J. Alexander Heimel, ${ }^{3}$ and ${ }^{\circ}$ Pieter R. Roelfsema ${ }^{1,4,5}$ \\ ${ }^{1}$ Department of Vision and Cognition, ${ }^{2}$ Department of Molecular Visual Plasticity, and ${ }^{3}$ Department of Cortical Structure and Function, Netherlands \\ Institute for Neuroscience, $1105 \mathrm{BA}$, Amsterdam, the Netherlands, ${ }^{4}$ Department of Integrative Neurophysiology, Center for Neurogenomics and Cognitive \\ Research, VU University, 1081 HV Amsterdam, the Netherlands, and ${ }^{5}$ Psychiatry Department, Academic Medical Center, 1100 DD Amsterdam, the \\ Netherlands
}

The firing rates of neurons in primary visual cortex (V1) are suppressed by large stimuli, an effect known as surround suppression. In cats and monkeys, the strength of suppression is sensitive to orientation; responses to regions containing uniform orientations are more suppressed than those containing orientation contrast. This effect is thought to be important for scene segmentation, but the underlying neural mechanisms are poorly understood. We asked whether it is possible to study these mechanisms in the visual cortex of mice, because of recent advances in technology for studying the cortical circuitry in mice. It is unknown whether neurons in mouse V1 are sensitive to orientation contrast. We measured the orientation selectivity of surround suppression in the different layers of mouse V1. We found strong surround suppression in layer 4 and the superficial layers, part of which was orientation tuned: iso-oriented surrounds caused more suppression than cross-oriented surrounds. Surround suppression was delayed relative to the visual response and orientation-tuned suppression was delayed further, suggesting two separate suppressive mechanisms. Previous studies proposed that surround suppression depends on the activity of inhibitory somatostatin-positive interneurons in the superficial layers. To test the involvement of the superficial layers we topically applied lidocaine. Silencing of the superficial layers did not prevent orientation-tuned suppression in layer 4. These results show that neurons in mouse V1, which lacks orientation columns, show orientation-dependent surround suppression in layer 4 and the superficial layers and that surround suppression in layer 4 does not require contributions from neurons in the superficial layers.

Key words: laminar; mouse visual cortex; orientation; scene segmentation; surround suppression; V1

\section{Introduction}

Visual perception is strongly influenced by context. A clear example can be seen in Figure 1. Perception of the contrast of the central grating is suppressed by the addition of a surround grating of the same orientation, but this suppression is greatly reduced if the surround orientation is rotated by $90^{\circ}$ (Cannon and Fullenkamp, 1991). It is thought that this effect exists to enhance the contrast between potential objects and their backgrounds, and it has been shown to be important in pop-out detection (Joseph and Optican, 1996). These perceptual effects are accompanied by

\footnotetext{
Received Dec. 3, 2013; revised April 25, 2014; accepted May 31, 2014.

Author contributions: M.W.S., J.A.M.L., J.A.H., and P.R.R. designed research; M.W.S., J.A.M.L., J.V., E.H.v.B., and J.A.H. performed research; C.N.L. contributed unpublished reagents/analytic tools; M.W.S., E.H.v.B., and M.E.G. analyzed data; M.W.S. and P.R.R. wrote the paper.

This work was supported by an NWO-VICI Grant and the EU Seventh Framework Program (project 269921 "BrainScaleS" and PITN-GA-2008-290011 "ABC") awarded to P.R.R., J.A.H. was supported by an NWO-VIDI Grant, J.V. was supported by an IEF-EU Marie Curie Fellowship, and M.E.G. was supported by the American/ Romanian foundation.

*M.W.S., J.A.M.L., and J.V. contributed equally to this work

The authors declare no competing financial interests.

Correspondence should be addressed to Matthew Self, Department of Vision and Cognition, Netherlands Institute for Neuroscience, Meibergdreef 47, 1005 BA, Amsterdam, the Netherlands. E-mail: m.self@nin.knaw.nl.

DOI:10.1523/JNEUROSCI.5051-13.2014

Copyright $\odot 2014$ the authors $\quad 0270-6474 / 14 / 349290-15 \$ 15.00 / 0$
}

equivalent changes in the activities of neurons in primary visual cortex (V1), which are suppressed if stimuli extend beyond their receptive field (RF; Knierim and van Essen, 1992; Levitt and Lund, 1997; Jones et al., 2001; Sceniak et al., 2001). The strength of this suppression depends strongly on the orientation of the surround elements (Nelson and Frost, 1978; Knierim and van Essen, 1992). Surrounds which are iso-oriented with respect to the center produce stronger suppression than cross-oriented surrounds. This orientation-dependent suppression reduces responses to uniform regions of a visual scene leading to a relative enhancement of activity evoked by cross-oriented stimuli. Accordingly, orientation-tuned surround suppression has been suggested to play an important role in figure-ground segregation (Lamme, 1995) and perceptual pop-out (Knierim and van Essen, 1992).

The neural mechanisms of surround suppression and its orientation sensitivity remain under debate. Many studies have shown surround suppression in the lateral geniculate nucleus of the thalamus (LGN; Jones et al., 2000; Solomon et al., 2002; Bonin et al., 2005; Sceniak et al., 2006; Alitto and Usrey, 2008), and it is likely that part of the suppression observed in V1 is inherited from the LGN. However, V1 might also contribute to surround suppression itself as suppressive surrounds are consid- 


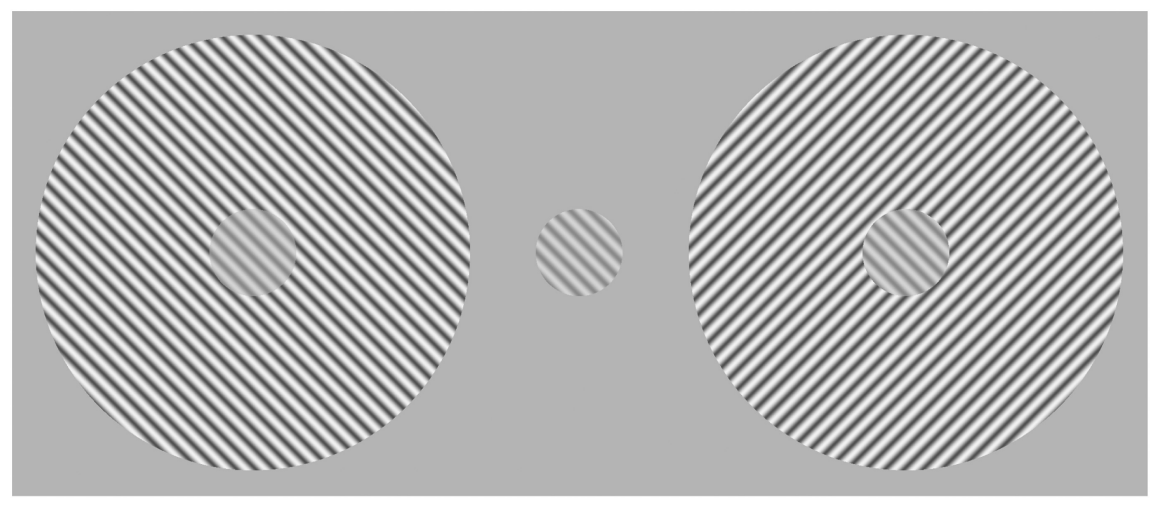

Figure 1. The effect of orientation context on perceived contrast. The center gratings are identical in all three figures. The addition of an iso-oriented grating (left image) reduces the perception of contrast of the center grating whereas a surround that is rotated by $90^{\circ}$ (right image) leaves perceived contrast unaffected or even enhances perceived contrast. the well was filled with warm Ringer's solution, which was regularly replenished during the recording session. The well allowed us to topically apply lidocaine to the dural surface. Lidocaine was applied by replacing the fluid in the well with a warm $\left(37^{\circ} \mathrm{C}\right)$ lidocaine solution $\left(20 \mathrm{mg} \cdot \mathrm{ml}^{-1}\right.$ stock solution of lidocaine hydrochloride diluted in Ringer's solution to a final concentration of $2-4 \mathrm{mg} \cdot \mathrm{ml}^{-1}$ ) for $30 \mathrm{~s}$. After this period the lidocaine solution was removed using suction and replaced with warm Ringer's solution.

We recorded simultaneously from every layer of primary visual cortex using a 16 contact laminar electrode (NeuroNexus A1x16-10 $\mathrm{mm}-100-413$, contacts spaced $100 \mu \mathrm{m}$ apart). Electrical signals from each of the contacts were amplified and digitized at $24.4 \mathrm{KHz}$ (Tucker-Davis Technologies). We measured the local field potential (LFP) using a low-pass erably larger in V1 than in the LGN (Jones et al., 2000; Bonin et al., 2005; Ozeki et al., 2009) and the orientation sensitivity of the effect suggests a cortical origin. A recent study (Adesnik et al., 2012) provided an important step toward understanding the neural circuitry of surround suppression by demonstrating that somatostatin-expressing interneurons in the superficial layers of mouse V1 mediate a proportion of the suppressive surround effects. Although this study did not investigate the orientation tuning of the surround effect, it illustrates the potential of studying mouse visual cortex for unlocking underlying circuit mechanisms and suggests that similar techniques could also be applied to investigate orientation-tuned surround suppression. Therefore, we asked whether surround suppression in the mouse is orientation dependent, just as in carnivores and primates, given that mouse V1 lacks the well structured orientation maps found in these other species (Ohki et al., 2005). We addressed this question by recording neuronal activity in the different layers of $\mathrm{V} 1$ in anesthetized mice and by determining the laminar profile and orientation tuning of surround suppression. We then investigated the contribution of neurons in the superficial layers of V1 to surround suppression by blocking activity in these layers with lidocaine.

\section{Materials and Methods}

Surgery and electrophysiology. All experimental procedures complied with the National Institutes of Health Guide for Care and Use of Laboratory Animals, and were approved by the Institutional Animal Care and Use Committee of the Royal Netherlands Academy of Arts and Sciences. We recorded data from electrode penetrations in 20 hemispheres of 16 male C57BL/6 mice, aged 5-8 weeks. We recorded size-tuning data from all hemispheres; in 16 hemispheres (10 animals) we studied the orientation tuning of the surround and in 9 of these ( 6 animals) we topically applied lidocaine. We additionally recorded from 13 hemispheres (11 animals) in which we presented static gratings (see below). Animals were sedated by brief exposure to $5 \%$ isoflurane in oxygen after which they were injected with $1300 \mathrm{mg} / \mathrm{kg}$ urethane intraperitoneally and $8 \mathrm{mg} / \mathrm{kg}$ of chlorprothixene subcutaneously. Additionally, $10 \mathrm{mg} / \mathrm{kg}$ dexamethasone and $0.1 \mathrm{mg} / \mathrm{kg}$ atropine were administered subcutaneously. To monitor depth of anesthesia, we tested foot reflexes by carefully pinching between the toes. When necessary, an additional dose of $200 \mathrm{mg} / \mathrm{kg}$ urethane was injected subcutaneously. Body temperature was maintained at $36.5^{\circ} \mathrm{C}$. Anesthetized animals were head fixed with ear and mouth bars in a stereotactic frame. A reference wire $(\mathrm{Ag} / \mathrm{Cl})$ was inserted between the skull and the dura of the frontal cortex while a ground electrode was inserted under the skin. A craniotomy with a radius $<0.5 \mathrm{~mm}$ was performed at $0.4 \mathrm{~mm}$ anterior of lambda and $2.9 \mathrm{~mm}$ lateral to the midline. A small well was built around the craniotomy using dental cement, and filter (corner frequency $200 \mathrm{~Hz}$ ) and sampled at $763 \mathrm{~Hz}$. We used the LFP power between 1 and $100 \mathrm{~Hz}$ to judge the depth of anesthesia. To this aim, we calculated a ratio between the mean power per frequency bin in the low frequencies $(2-8 \mathrm{~Hz})$ and the mean power per frequency bin across all frequencies $(1-100 \mathrm{~Hz})$ and judged anesthesia to be deep if this ratio was $>1.65$. This objective assessment agreed well with our subjective on-line assessment of anesthetic depth based on the presence of up-down states in the activity of single units and multiunit activity.

We calculated current-source density (CSD) as the second spatial derivative of the LFP (Mitzdorf, 1985):

$$
\operatorname{CSD}(x)=-\sigma \cdot \frac{\phi(x-h)-2 \phi(x)+\phi(x+h)}{h^{2}},
$$

where $\varphi$ is the voltage, $x$ is the point at which the $\operatorname{CSD}\left(\right.$ in $\left.\mathrm{A} \cdot \mathrm{mm}^{-3}\right)$ is calculated, $h$ is the spacing of recording sites for the computation (here $0.2 \mathrm{~mm}$ ), and $\sigma$ is the tissue conductivity (we used $400 \mathrm{~S} \cdot \mathrm{mm}^{-1}$; Logothetis et al., 2007). We used the CSD response to the onset of a full-screen, full-contrast checkerboard stimulus ( check size $=20^{\circ}$ ) to place the electrode at approximately the same depth for each penetration. We examined the CSD traces for the earliest current sinks induced by the checkerboard in combination with a reversal from current sources to current sinks as these features mark the location of the boundary between layers 5 and 4c (Mitzdorf, 1985; Fig. 2). This reversal agrees well with histological assignments of this laminar boundary in mice (Niell and Stryker, 2008). Individual recording sites were assigned to the different layers on the basis of their distance from this boundary. Sites from -500 to $-100 \mu \mathrm{m}$ were assigned to the deep layers, $0-100 \mu \mathrm{m}$ to layer 4 , and $200-400 \mu \mathrm{m}$ to the superficial layers.

We recorded single-unit activity by setting a spike-amplitude threshold for each recording site. To isolate single units, we clustered spike shapes using WaveClus (Quiroga et al., 2004) and only included well separated clusters with a refractory period in our single-unit analysis. We also recorded multi-unit activity (MUAe, where " $e$ " stands for envelope; (Supèr and Roelfsema, 2005). To record MUAe, the signal from the electrode was bandpass filtered $(500 \mathrm{~Hz}-5 \mathrm{kHz})$ to extract highfrequency (spiking) activity, rectified, and then low-pass filtered at 200 $\mathrm{Hz}$ to measure the envelope of this signal. MUAe provides an instantaneous measure of the number and amplitude of spikes in the vicinity of the electrode without the setting of a spike-detection threshold. MUAe responses are similar to thresholded multi-unit data and to the average single-unit response (Supèr and Roelfsema, 2005; Self et al., 2012). For recordings in which we assessed the effect of topical application of lidocaine we used thresholded MUAs to judge the silencing of spiking activity in the superficial layers. To record MUAs, the signal from the electrode was bandpass filtered $(500 \mathrm{~Hz}-5 \mathrm{kHz})$ and a spike-amplitude threshold was set to be four times the root mean square amplitude of the signal.

Visual stimuli. Stimuli were projected onto a back-projection screen placed $15 \mathrm{~cm}$ from the mouse using a gamma-corrected PLUS U2-X1130 
DLP projector (mean luminance $=40.6$ $\left.\mathrm{cd} \cdot \mathrm{m}^{-2}\right)$. The MUAe RF of every recording site was mapped using a briefly $(200 \mathrm{~ms})$ presented $10^{\circ}$ bright square presented at each point of a grid covering the entire screen $\left(136^{\circ} \times 102^{\circ}\right.$; Fig. 2$)$. We then determined the preferred tuning properties of the multi and single units using drifting gratings in blocks of at least 20 repeats of either $0.5 \mathrm{~s}$ or $1 \mathrm{~s}$ duration drifting gratings (mean luminance 40.6 $\mathrm{cd} \cdot \mathrm{m}^{-2}$, contrast $80 \%$ ) in which we varied spatial frequency (values $=0.01,0.05,0.1$, and $0.2 \mathrm{cyc}^{\circ} \cdot \operatorname{deg}^{-1}$ ), drift speed (values $=12,18$, $\left.24,30,36 \mathrm{deg} \cdot \mathrm{s}^{-1}\right)$, and the orientation of the grating $\left(0-360^{\circ}\right.$ in 12 steps of $\left.30^{\circ}\right)$. MUAe activity at each recording site was averaged to construct tuning curves and the predominantly preferred values were chosen. We then measured size-tuning profiles using gratings of the predominantly preferred stimulus for the penetration. We presented $0.5 \mathrm{~s}$ drifting sine wave gratings of nine aperture sizes from 5 to $100^{\circ}$. Grating presentations were separated by a $0.5 \mathrm{~s}$ intertrial interval with a gray screen of mean luminance. For some penetrations $(n=$ 8 ) we used gratings of $1 \mathrm{~s}$ duration and obtained similar results, therefore we combined results from 0.5 and $1 \mathrm{~s}$ durations.

For experiments in which we assessed the orientation tuning of the surround $(n=16)$ we chose two center grating sizes: a relatively small grating $\left(\right.$ mode $=20^{\circ}$, range $15-30^{\circ}$ ) with the same diameter as the preferred size of the MUAe RFs in layer 4 (as judged by the sizetuning curve, see below) and a grating, which was $20^{\circ}$ larger. We added a surround grating with an outer diameter of $120^{\circ}$ and an inner diameter abutting the central grating. Both gratings drifted at the preferred speed that had been determined for that penetration. We implemented a $2 \times 2 \times 2$ factorial design with the (1) size of the central grating (small or large),

(2) orientation of the central grating ("predominant" or "orthogonal"), and (3) relative orientation of the surround (iso- or cross-oriented) as factors. We also included conditions in which the surround gratings were presented in isolation to assess the activation of the RF by the surround and a condition with a gray screen to assess spontaneous activity. The other properties of the grating(s) were identical to those used for measuring size tuning, except that the stimulus duration was now always $1 \mathrm{~s}$. In a subset of experiments $(n=13)$ we measured the responses to static gratings. These stationary gratings were identical to the drifting gratings except that the phase was randomly chosen on each trial between $-\pi$ and $\pi$ and the stimulus duration was $0.5 \mathrm{~s}$.

Data analysis. To measure size-tuning curves we fit the average response between 0 and $0.5 \mathrm{~s}$ after stimulus onset with a ratio-of-Gaussians model (ROG), which provides a good fit to size-tuning curves (Sceniak et al., 2001; Cavanaugh et al., 2002; Van den Bergh et al., 2010):

$$
R(x)=\frac{G_{e}\left[\operatorname{erf}\left(\frac{x}{W_{e}}\right)\right]^{2}}{1+G_{i}\left[\operatorname{erf}\left(\frac{x}{W_{i}}\right)\right]^{2}} .
$$

$G_{e}, G_{i}, W_{i}$, and $W_{e}$ are the gains and widths of the excitatory center and inhibitory surround, respectively; $x$ is the size of the grating in degrees; $R(x)$ is the response; and erf is the error function. The model was fit to SUA data using the mean evoked firing rates for each size. For MUAe data we first normalized the MUAe responses by subtracting the mean MUAe activity in the prestimulus period $(-0.2$ to $0 \mathrm{~s})$ then dividing by the
LFP

CSD

Figure 2. RF measurements and determination of layer boundaries. Left, Illustrates the MUAe responses evoked by briefly a $10 \times 10^{\circ}$ white square on a black screen. Responses were normalized to the peak response across all positions. The black was relatively constant across the layers (although a small degree of drift can be seen) and RF diameter was $\sim 20^{\circ}$. Middle, Shows 列 the different laminar compartments based on the distance to this highly reproducible boundary (defined as depth $=0$ ), as indicated with colored numbers in the middle part (blue, deep; green, layer 4; red, superficial).

maximum response over the entire stimulus duration, across all sizes. We excluded single units with a mean stimulus-evoked firing rate of $<0.5 \mathrm{~Hz}$ (32\% of units) and also excluded fits to the size-tuning curves if the $r^{2}$ was smaller than 0.3 ( $10 \%$ of units) leaving a total of 106 units for analysis. The preferred size was taken as the smallest size at which the fitted curve reached the maximum response, and only for cells that had a surround suppression index (SI) of greater than zero. The surround SI was calculated as follows:

$$
S I=\frac{R_{\max }-R_{100}}{R_{\max }}
$$

where $R_{\max }$ was the estimated evoked neural response (SUA firing rates or normalized MUAe) to the grating size that gave the maximal response (estimated from the fitted curve) and $R_{100}$ was the response to the largest grating.

In experiments in which we assessed the orientation tuning of the surround we recorded from a total of 150 cells. We excluded cells that had a mean evoked firing rate of $<0.5 \mathrm{~Hz}$ ( $40 \%$ of cells) leaving 90 cells for analysis. We quantified the difference between the cross- and isooriented conditions for each cell using an orientation-specific suppression index (OSSI), which was calculated as follows:

$$
\operatorname{OSSI}_{z}=\frac{C_{z}-I_{z}}{C_{z}+I_{z}}
$$

where $C_{z}$ is the mean number of stimulus-evoked spikes (between 0 and $1 \mathrm{~s}$ after stimulus onset) on trials with a center of size $z$ (i.e., the smaller or 
larger center size) and a cross-oriented surround and $I_{z}$ is the mean number of stimulus-evoked spikes on iso-oriented surround trials, with the mean calculated across the two center orientations. We also calculated $\operatorname{OSSI}_{z}$ for MUAe responses by applying the same equation to the average MUAe activity between 0 and $1 \mathrm{~s}$ after stimulus onset for drifting gratings or $0-0.5 \mathrm{~s}$ for static gratings.

In one of our control analyses we selected a subpopulation of cells with a clear preference for one of the two center orientations. We calculated an orientation-preference index (OI), which assesses the strength of the orientation preference of the cell:

$$
O I=\frac{\text { Cent }_{\text {pref }}-\text { Cent }_{\text {orth }}}{\text { Cent }_{\text {pref }}+\text { Cent }_{\text {orth }}},
$$

where Cent $t_{\text {pref }}$ was the evoked response to the preferred orientation and Cent $_{\text {orth }}$ the response to the orthogonal orientation. We selected only those cells with OIs $>0.111$ for both sizes, equivalent to a difference in firing rate between the two orientations of $25 \%$. We will refer to these cells as "well tuned."

Latencies of MUAe responses were estimated by fitting a curve to the response elicited by the center-only conditions. We fitted the combination of a Gaussian and a cumulative Gaussian with a nonlinear leastsquares fitting method:

$$
y(t)=\frac{G_{1} e^{-0.5\left(\frac{t-\mu_{1}}{\sigma_{1}}\right)^{2}}}{\sqrt{2 \pi} \sigma_{1}}+0.5 G_{2}\left[1+\operatorname{erf}\left(\frac{t-\mu_{2}}{\sigma_{2} \sqrt{2}}\right)\right]
$$

where $y(t)$ is the estimated MUAe response at time $t, G_{1}$ and $G_{2}$ determine the amplitude of the Gaussians, $\mu_{1}$ and $\mu_{2}$ their means, and $\sigma_{1}$ and $\sigma_{2}$ their SDs. The first term of this equation captures the initial peak response and the second term the sustained phase. We also fitted versions of this equation with only the first or second term and chose the fit with the lowest Akaike information criteria value. Latencies were estimated as the time point at which the fitted curve reached $33 \%$ of its first maximum. In our analysis of latencies, we only included cases for which the fitted curve explained at least $30 \%$ of the variance. To estimate the latencies of differences in response magnitude between conditions we used the same procedure, fitting the curve to the difference response at individual recording sites. To estimate the rate of change of the response we used the slope of the fitted response, which was measured as follows:

$$
\text { Slope }=\frac{1}{\sigma_{e}}
$$

where $\sigma_{e}$ was the SD of the term with the smallest $\mu$, which captures the onset of the response. Higher slope values indicate that neural activity (differences) changed more rapidly.

For experiments in which we topically applied lidocaine $(n=9)$ we first recorded a predrug block of data using the same stimuli as for the experiments assessing the orientation tuning of the surround. We then applied lidocaine for $30 \mathrm{~s}$ (see above) and immediately began recording. We created an analysis window from the moment of drug application to the time point at which responses in the superficial layers had returned to $75 \%$ of their predrug values. This was assessed using the MUAs responses to the center-only condition. Recovery times varied from 5 to $15 \mathrm{~min}$ (median $=8 \mathrm{~min}$ ). The brief duration of the effect and the excellent recovery from the drug allowed us to make multiple applications for each penetration. We made a total of 21 applications of lidocaine, with a maximum of 3 applications per penetration. Statistical analysis was performed at the level of applications, although identical results were obtained when only one application was included per penetration. Lidocaine reduces baseline firing rates. We therefore estimated the baseline firing rate with a running average of the MUAs activity in the prestimulus time period ( -0.2 to $0 \mathrm{~s}$ relative to stimulus onset). We used a LOWESS regression with a time span of $60 \mathrm{~s} \mathrm{(MATLAB;} \mathrm{MathWorks).}$ We normalized MUAs in the lidocaine experiment by first subtracting the estimate of baseline and then dividing by the maximum of the average response to the center-only condition in the predrug period. We also calculated the percentage change in MUAs response produced by the drug. This was calculated as follows:

$$
\text { Percentage change }=\frac{\text { Pre }- \text { Drug }}{\text { Pre }},
$$

where Pre was the mean-evoked MUAs response to the center-only condition (averaged across both sizes) in the time period $0-1 \mathrm{~s}$ after stimulus onset and Drug was the same but for the drug analysis period. This index was used to select penetrations in which the drug was effective but did not penetrate too deeply. Only penetrations in which the percentage change was $>33 \%$ in the superficial layers and $<33 \%$ in layer 4 were selected for further analysis $(n=11)$.

Due to time constraints we could not measure the full size-tuning curves after lidocaine application. To quantify the level of surround suppression for the lidocaine experiments we defined an index $\left(\mathrm{SI}_{\text {Centsurr }}\right)$, based on the responses to the stimuli used to measure the orientation tuning of surround suppression:

$$
S I_{\text {CentSurr }}=\frac{\mathrm{C}_{\text {small }}-\text { Iso }}{\mathrm{C}_{\text {small }}+\text { Iso }}
$$

where $C_{\text {small }}$ was the mean-evoked MUAs response to the small-sized center grating (from 0 to $1 \mathrm{~s}$ after stimulus onset) and Iso was the mean response to the iso-oriented surround condition (which was identical in appearance for the two center sizes).

\section{Results}

We recorded single- and multi-unit neural activity from each layer of anesthetized mouse V1 using a laminar electrode (NeuroNexus). The electrode was placed at the same depth in cortex each day using CSD analysis to locate the boundary between layers 4 and 5 (Fig. 2). We then localized the multi-unit RF at each recording contact (Fig. 2) and determined the preferred stimulus of each multi-unit site using drifting sine wave gratings of varying spatial/temporal frequency and orientation. Because we recorded from multiple sites at the same time, we had to choose values that were the best compromise across the layers (spatial frequency: mode $=0.05 \mathrm{cyc} \cdot \mathrm{deg}^{-1}$, range $=0.05-0.08 \mathrm{cyc} \cdot \mathrm{deg}^{-1}, \mathrm{drift}$ speed: mode $=24 \mathrm{deg} \cdot \mathrm{s}^{-1}$, and range $\left.=18-36 \mathrm{deg} \cdot \mathrm{s}^{-1}\right)$. We then measured size-tuning curves by varying the outer diameter of the grating aperture to assess the level of surround suppression.

\section{Influence of anesthesia on surround suppression}

We first determined how the depth of anesthesia affects surround suppression. Recent studies have suggested that the strength of surround suppression is weaker under anesthesia (Adesnik et al., 2012; Haider et al., 2013); however, the precise relationship between surround suppression and depth of anesthesia is unknown. We observed a strong effect of the level of anesthesia, which was assessed by the prominence of low-frequency power in the LFP (see Materials and Methods), on the strength of surround suppression. Figure $3 B$ shows the responses of a single cell from layer 4 measured under deep anesthesia (Fig. 3A, blue curve; power ratio $=1.76$ ). The cell did not exhibit strong surround suppression, because the response increased for grating sizes up to 40 degrees and then reached a plateau (Fig. $3 B$ ). We quantified the size-tuning curves by fitting an ROG model (see Materials and Methods) and measured surround suppression with an SI (see Materials and Methods), defined as the difference in response to a stimulus of the preferred size and the largest size we used $\left(100^{\circ}\right)$ divided by the response to the largest size. The SI of the example cell under deep anesthesia was only 0.05 indicating almost no suppression. Figure $3 A$ illustrates that the anesthesia was lighter $2 \mathrm{~h}$ later (red power spectrum, power ratio $=1.52$ ), although the animal was still well anesthetized as judged from the foot pinch 
A

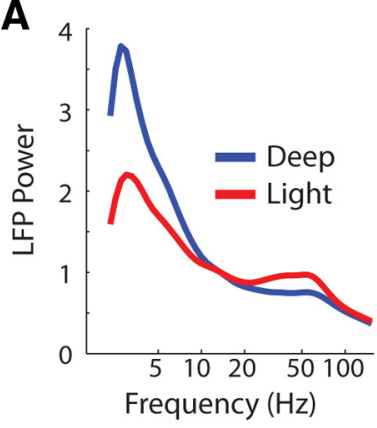

C
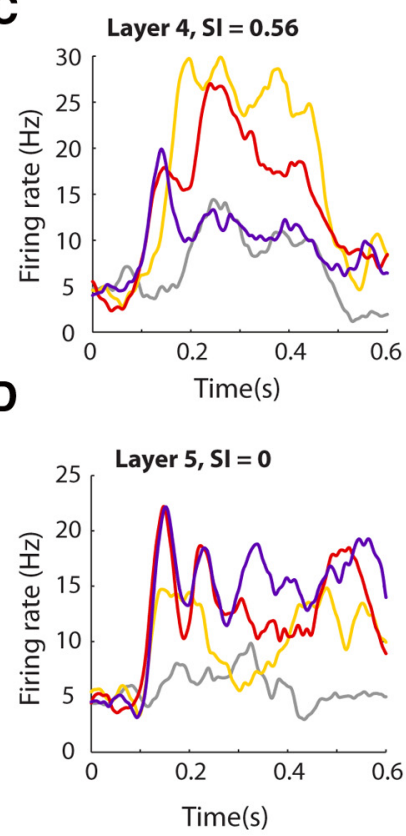
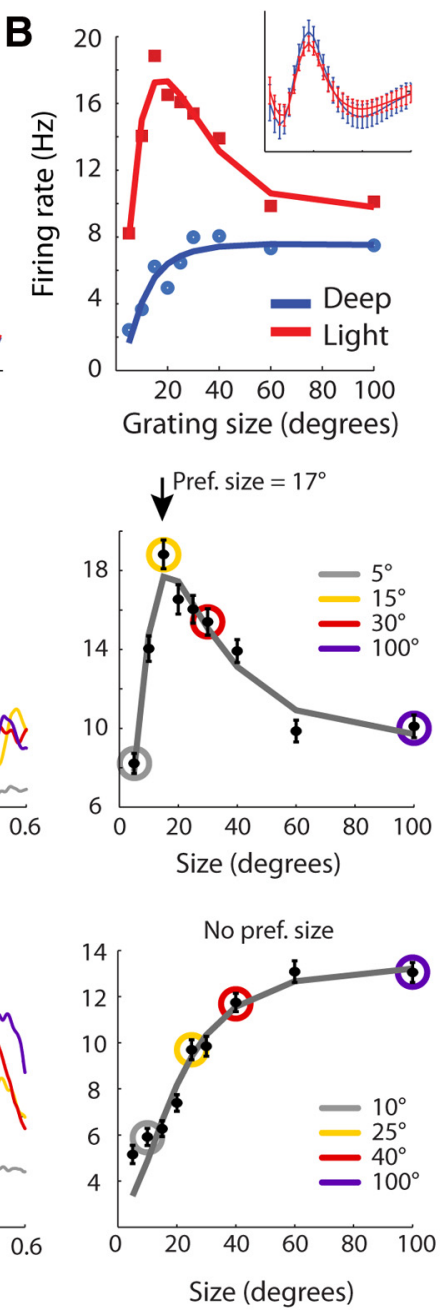

E

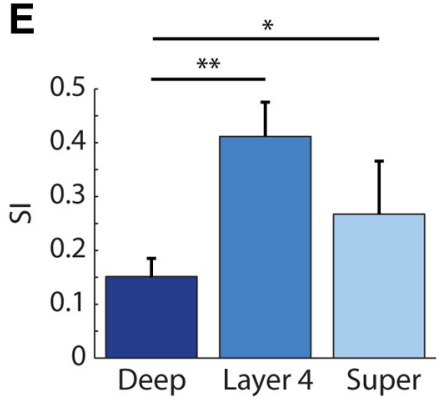

G

\section{禀}
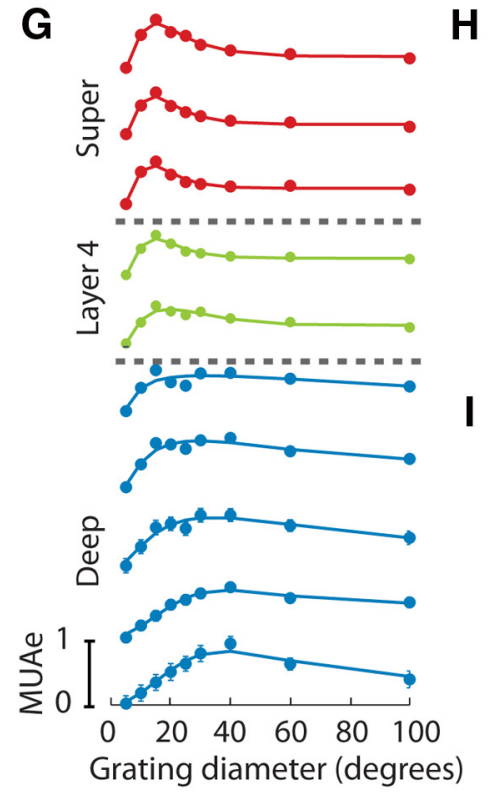

$\mathbf{F}$
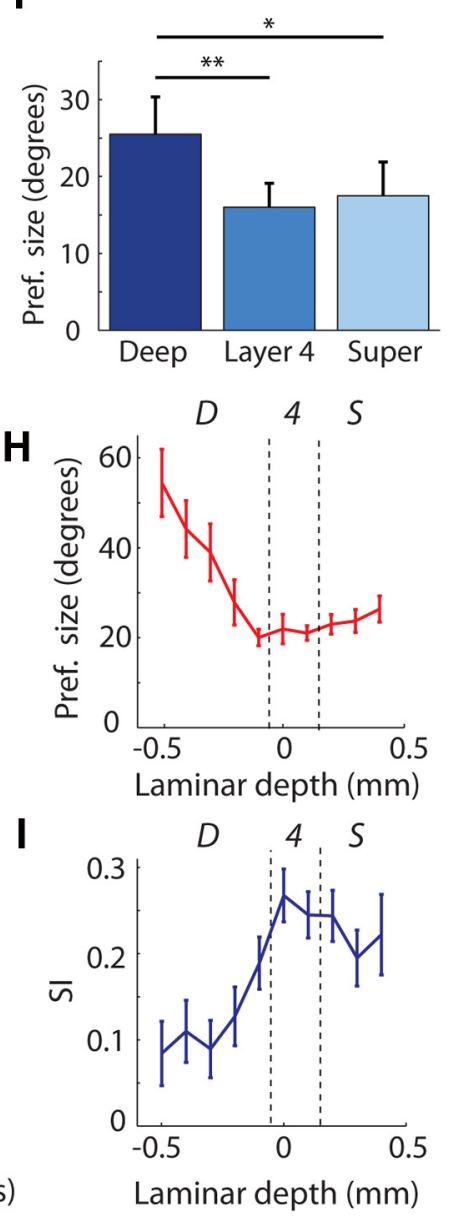

Figure 3. Size tuning in the different layers of V1. $A$, We judged the depth of anesthesia using the LFP as the relative contribution of low-frequency power (2-8 Hz) to the power spectrum of the LFP. The average power across layers is shown at two different time points ( $2 \mathrm{~h}$ apart) of a single penetration. $\boldsymbol{B}$, Size-tuning curves from a single neuron in layer 4 recorded under both deep and light anesthesia. The inset shows the average spike waveform of the cell under the two states of anesthesia. $\boldsymbol{C}$, An example single unit from layer 4 (the same cell as in $\boldsymbol{A}$ ). The left plot shows the PSTH for four of the grating sizes. The right plot shows the size-tuning curve; the sizes shown on the left are indicated with colored circles. $D$, An example unit in the deep layers without surround suppression. $\boldsymbol{E}$, Median SI across different layers. Significant differences between compartments as judged by Wilcoxon signed-rank tests are indicated by the asterisks $\left({ }^{*} p<0.05,{ }^{* *} p<0.01\right)$. Error bars show bootstrap estimates of SEM. $\boldsymbol{F}$, The median preferred size as assessed by the size-tuning curves across the population of single units for the different layers. $\mathbf{G}$, MUAe size-tuning curves recorded simultaneously from different layers of a single penetration. Surround suppression was strongest in layer 4 and the superficial layers. $\boldsymbol{H}$, The median MUAe RF size in different layers across the population of 200 recording sites. $I$, The median SI revealed stronger suppression in layer 4 and the superficial layers than in the deep layers. Error bars are bootstrap estimates of SEM.

reflex. The spontaneous firing rate of the cell, which had been 1.7 spikes $\cdot \mathrm{s}^{-1}$ under deeper anesthesia, increased to 5.3 spikes $\cdot \mathrm{s}^{-1}$ and the responses evoked by the gratings also increased. Interestingly, the cell was now suppressed by large gratings; the sizetuning curve showed a prominent peak at $15^{\circ}$ and responsiveness declined as the grating size was increased. The SI increased to 0.65 indicating very strong suppression. These results were replicated across a population of 17 single units recorded under both deep and light anesthesia. The median SI increased from 0.04 under deep anesthesia to 0.37 under lighter anesthesia (Wilcoxon ranksum test, $p=0.01$ ). These findings indicate that deep anesthesia reduces the strength of surround suppression. As the goal of our study was to determine the laminar profile of surround suppression, we limited our further analyses to the lighter anesthetic states where surround suppression was strongest.

\section{Laminar profile of surround suppression}

We next investigated how surround suppression varied across the different layers of V1 in 20 penetrations as recent studies have found large laminar differences in the strength of surround suppression (Vaiceliunaite et al., 2013). Figure $3 C$ shows peristimulus time histograms (PSTHs) and size-tuning curves from an example cell in layer 4 (the same cell as in Fig. $3 B$ ). The very early responses of this cell were strongest for the largest sizes (note the early response to gratings of 30 and $100^{\circ}$ ). However, after $\sim 130$ $\mathrm{ms}$ the responses to the larger stimuli became suppressed whereas the response to the $15^{\circ}$ stimulus increased further. Figure $3 D$ provides a representative example of a cell in the deep layers with no surround suppression ( $\mathrm{SI}=0$ ). Across the population of single units, we found that the strength of surround suppression (as judged by the SI) varied significantly across the layers (KruskalWallis test, $p=0.004$ ) and was significantly weaker for cells in the deep layers than both layer 4 and the superficial layers (Fig. 3E; Wilcoxon rank-sum test, both $p<0.05$ ). However, surround suppression in layer 4 did not differ significantly from that in the superficial layers $(p=0.5)$. The cells' preferred sizes also varied significantly across the layers (Kruskal-Wallis test, $p=0.004$ ), and was significantly larger in the deep layers than both layer 4 
and the superficial layers (Fig. 3F; Wilcoxon rank-sum tests, both $p<0.05)$. We considered the possibility that laminar differences in SI may be a result of differences in visual responsiveness, as a previous study reported that surround suppression is weaker for cells that are poorly driven by the stimulus (Schwabe et al., 2010). We took the maximum evoked response across all sizes as a measure of the cell's responsiveness. Responsiveness differed between the layers ( $p=0.002$, Kruskal-Wallis test) and was slightly lower in the deep layers than in layer 4 and in the superficial layers [median $=4.0 \mathrm{~Hz}$ (deep), $9.2 \mathrm{~Hz}$ (layer 4), $4.9 \mathrm{~Hz}$ (superficial)]. However, in our sample of cells responsiveness did not correlate with SI $\left(r^{2}=0.006, p=0.46\right)$, which indicates that the difference in surround suppression between the layers was not caused by differences in visual responsiveness.

The above single-unit analyses suggest that surround suppression is stronger in layer 4 and the superficial layers than in deep layers. It is difficult to construct a fine-grained spatiotemporal profile of surround suppression strength using single units because well isolated units may not be present at every depth and stimulus-evoked firing rates are usually low (Niell and Stryker, 2008). To investigate the laminar profile of surround suppression at a finer scale and to assess latencies, we analyzed MUAe responses (see Materials and Methods). The preferred size of MUAe sites varied significantly across layers (Fig. 3G,H; KruskalWallis test, $p=4.9 \times 10^{-4}$ ) reaching a minimum in layer 4 (median $\mathrm{RF}=17.5^{\circ}$ ) and a maximum in layer 6 (median $\mathrm{RF}=$ $54^{\circ}$ ). Figure $3 G$ shows the MUAe size-tuning profiles of each layer from an example penetration. It can be seen that surround suppression was strongest in the superficial layers and weaker in the deep layers, just as was observed for the single-unit responses. Also at the population level, the strength of surround suppression (SI) in MUAe varied significantly across layers (Fig. 3I; KruskalWallis test, $p<10^{-6}$ ), and was significantly stronger in layer 4 $($ median SI $=0.25)$ and the superficial layers (median SI $=0.18$ ) than in the deep layers (median SI $=0.06$; Mann-Whitney $U$ test, all $\left.p<10^{-6}\right)$. Surround suppression strengths in the superficial layers and layer 4 were not significantly different $(U$ test, $p=0.14$ ).

\section{Orientation tuning of surround suppression in single units}

In carnivores and primates the strength of surround suppression depends upon the orientation of the surround grating. Suppression is strongest for iso-oriented surrounds and weakest for cross-oriented surrounds (i.e., when the surround grating is orthogonal to the center grating; Nelson and Frost, 1978; Knierim and van Essen, 1992; Sillito et al., 1995; Levitt and Lund, 1997; Shushruth et al., 2012). We tested the orientation tuning of surround suppression in mouse V1 neurons by presenting surround gratings that had the same or orthogonal orientation as the center grating (Fig. 4A). We simultaneously recorded from several single units during each penetration. It was therefore impossible to select an orientation for the center grating that was optimal for all cells. We instead used two different orientations for the center grating, one orientation that was predominantly preferred across the penetration (the predominant orientation; by chance more cells were observed to have orientation preferences close to this value, but this does not imply a columnar organization) and one orthogonal to this (the orthogonal center orientation). The results described below were averaged across these two orientations except where indicated. We also used two differently sized center gratings in this experiment. The "small" center grating was chosen to match the preferred size of cells in layer 4 as assessed by the size-tuning curve. However, as the preferred size varied across layers (Fig. $3 F, H$ ) this size was not optimal for deep layer cells.
We therefore also used a grating that was $20^{\circ}$ larger than the small grating and more closely matched to the preferred size of deep layer cells (the "large" grating).

We recorded from 16 penetrations in which we varied the orientation of the surround. Figure $4 B$ shows the responses of an example single unit from layer 4 to surrounds of different orientations. The addition of a surround reduced responses for the duration of the stimulus for both center sizes. This response decrease depended on the orientation of the surround. When the surround was iso-oriented, we observed significantly stronger suppression than when the surround was cross-oriented ( $U$ test, both center sizes: $p<10^{-4}$ ). We also observed significant activation of the cell when we presented the surround in isolation (Fig. $4 B$, green curve). Activation of the cell by the small-sized surround was expected as the small size was chosen to be at the maximum of the size-tuning curve, and it is likely that gratings of this size still exhibit slight overlap with the RF. Furthermore, there were always slight displacements of the center of the RF in different layers (Fig. 2), which made it impossible to fully center the grating in the RF for every layer. However, we even observed activations by the surround when the grating was well centered on the RF and the surround was entirely outside the classical RF. As expected, the activation by the large grating surround was much weaker than that by the small grating surround (Fig. $4 B$, right), but it remained significantly greater than zero. Thus, we found strong surround stimuli that are presented entirely outside the RF cause a weak V1 response. Although these paradoxical responses elicited from outside the classical RF may be enhanced under anesthesia (Haider et al., 2013), they have also been observed in area V1 of awake monkeys (Li et al., 2001; Pooresmaeili et al., 2010).

Across the population of 90 cells that we tested with surround gratings we found that the suppression elicited by the surround was greatly reduced when it was rotated by $90^{\circ}$ relative to the center. Single-neuron firing rates were significantly higher in the cross-condition than in the iso-condition when the center was stimulated by the grating of either size ("small": Wilcoxon signed-rank test, $p=0.01$ or "large": $p=0.005$; Fig. $4 C$ ). We found that the small center stimulus activated $37 \%$ of the single units significantly (as judged by a $U$ test, $p<0.05$ ) more strongly when accompanied by the cross-oriented compared with the isooriented surround, whereas only $17 \%$ had the opposite preference, which is a significant difference ( $p=0.001, z$-test). For the large center grating, the proportion of units with a significantly stronger response elicited by the orthogonal orientation was $19 \%$ whereas $4 \%$ preferred the iso-oriented stimulus $(p=0.001$, $z$-test). We quantified this effect across the different layers using an OSSI, defined as the difference between activity elicited in the cross- and iso-surround conditions (averaged across the two center orientations), normalized to the sum of the activity in the cross- and iso-surround condition (see Materials and Methods). OSSI indices were significantly greater than zero for both small and large center sizes in layer 4 (Wilcoxon signed-rank test, both $p<0.005$ ) and the superficial layers (both $p<0.05$; Fig. $4 D, E$ ) and there were no significant differences between these two laminar compartments ( $U$ test, $p>0.5$ ). The deep layers showed no significant modulation by the orientation of the surround at either size (Wilcoxon signed-rank test, both $p>0.05$ ).

We observed significant responses to the surround-only condition across the population of cells for both center sizes (Wilcoxon signed-rank test, both $p<0.001$ ). However, it is unlikely that direct RF activation by the surround caused the observed orientation-dependent suppression, as the OSSI was determined 


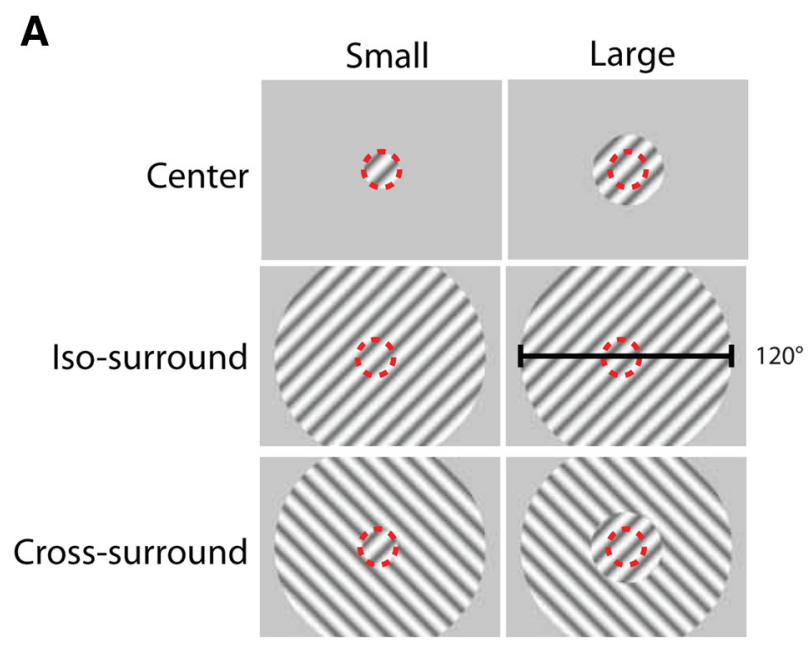

B

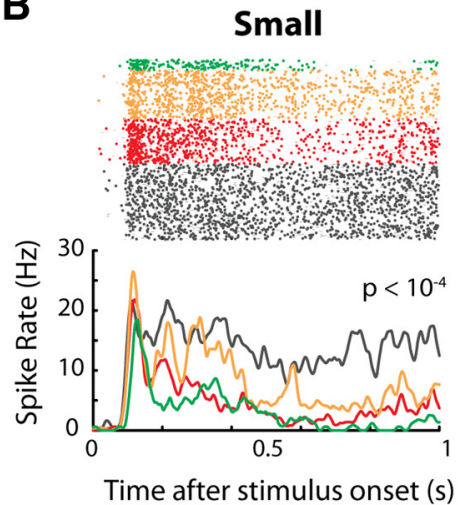

Small

- Cent - Iso

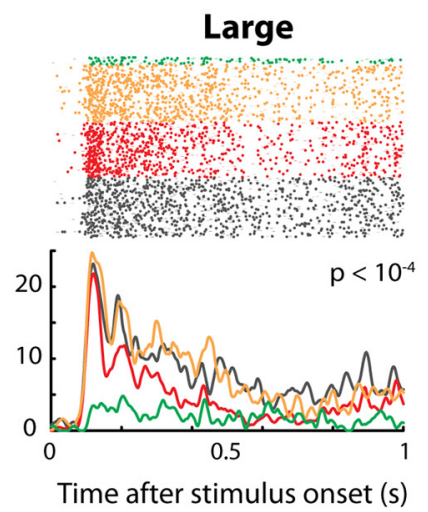

Cross - Surr
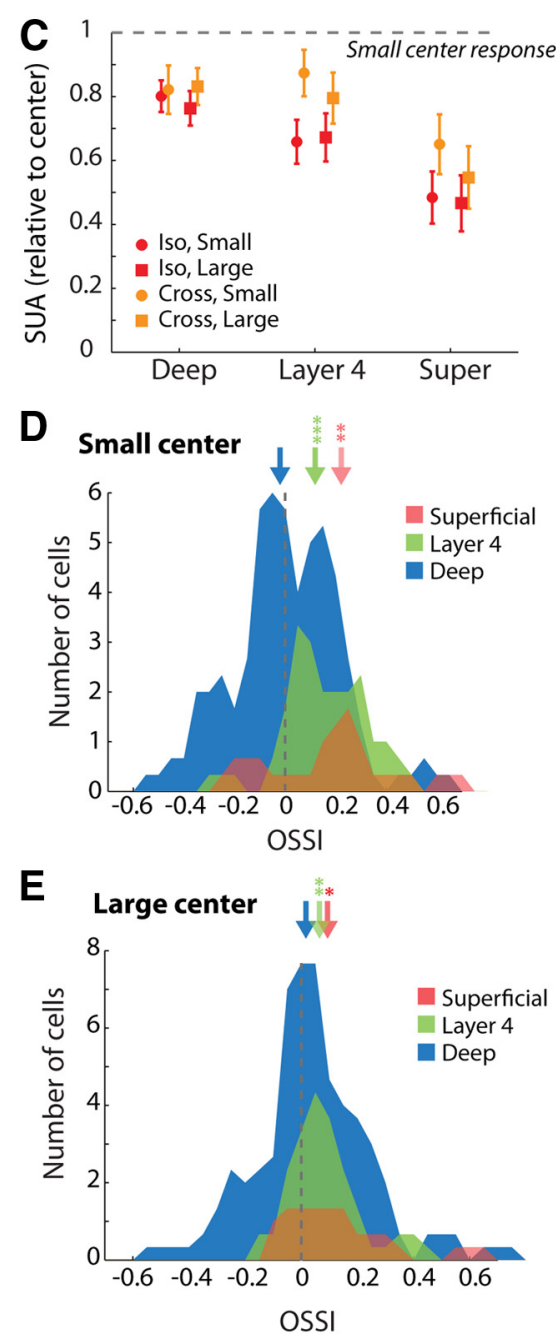

Figure 4. The effect of orientation context on single-unit responses in V1. $\boldsymbol{A}$, We presented drifting sine wave gratings of $80 \%$ contrast with two different center sizes. The "small" size was the preferred size of layer 4 cells (red dashed circle) and the "large" size was $20^{\circ}$ larger so that the edge of the grating fell outside all the RFs of a penetration (with the possible exception of some layer 6 neurons with very large RFs). We presented two orthogonal center orientations (only one is shown here) and the surround could either be iso-oriented (middle row) or cross-oriented (bottom row) relative to the center. The outer diameter of the surround grating was $120^{\circ}$. B, Spike rasters (top) of an example layer 4 cell evoked by the center grating with a small (left) or large size (right). The green spikes are elicited by the surround shown in isolation (there were half as many surround-only trials as the other conditions), orange spikes by the cross-oriented surround, red spikes by the iso-oriented surround, and gray spikes by the center-only stimulus. The PSTH averaged across the two center orientations is shown at the bottom. Stimuli with a cross-oriented surround (orange) elicited significantly stronger responses than stimuli with iso-oriented surrounds (red; $U$ test, $p<10^{-4}$ ). $C$, Average single-unit responses elicited in the three laminar compartments by the cross-oriented (orange) and iso-oriented surround (red) with a small (circles) or large-sized center grating (squares). The responses of individual cells were normalized by subtracting the spontaneous firing rate and dividing by the response to the small-sized center grating presented in isolation. $\boldsymbol{D}, \boldsymbol{E}, 0$ SSI of 90 single units in the three laminar compartments for the small ( $\boldsymbol{D}$ ) and large center grating $(\boldsymbol{E})$. The arrows show medians and the asterisks above them indicate significance based on Wilcoxon signed-rank tests $\left({ }^{*} p<0.05 ;{ }^{* *} p<0.01\right)$.

by averaging across the two center orientations. The four stimuli (two orientation and two surround conditions) were balanced, because on average the same local stimulus was presented at every visual field position for the cross- and isosurround stimuli. We performed a number of further analyses to investigate the contribution of surround-only responses to the orientation-specific surround suppression effect. First, we split the population of cells according to the strength of their response in the surround-only conditions. In each laminar compartment, we performed a median split, and investigated the $50 \%$ of cells with the lowest surround-only responses separately (Fig. 5A). Even the subpopulation of cells with weak surround-only responses exhibited stronger responses in the cross-oriented condition than in iso-oriented condition. Indeed, their OSSI was significantly larger than zero in layer 4 for both center sizes and in the superficial layers for the small center size (Fig. 5B; Wilcoxon signed-rank test, all $p<0.05$; the superficial layers also showed a strong trend for the large center size, $p=0.07)$. Second, the surround-only response did not predict the strength of the orientation-dependent surround suppression because the correlation between the surround-only response (normalized to the center-only response) and the OSSI was not significant for either surround size (both sizes, $r^{2}<0.01$, $p>0.3)$. We also examined this relationship for each laminar compartment and center orientation separately and found no significant correlations (all $r^{2}<0.08$, all $p>0.05$ ). Last we examined the responses elicited by the preferred and nonpreferred orientations of a set of well tuned cells $(n=31$; see Materials and Methods). We then examined the OSSI of these cells for their preferred or nonpreferred center orientation (Fig. 5C). The OSSI was significantly greater than zero for the large-sized stimuli, regardless of the orientation in the neurons' RF, in accordance with previous studies in awake macaque monkeys (Shushruth et al., 2012). Together, these results demonstrate that orientation- 
A

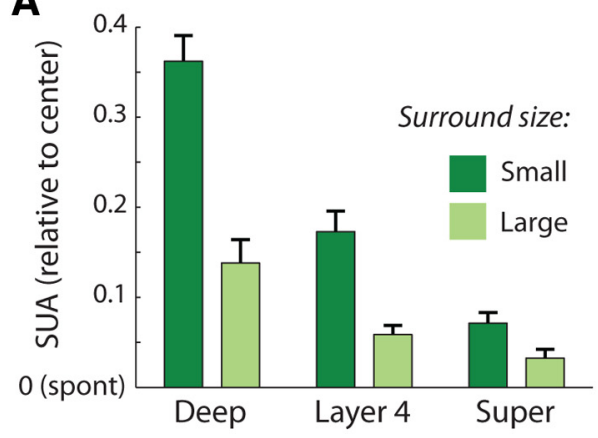

B

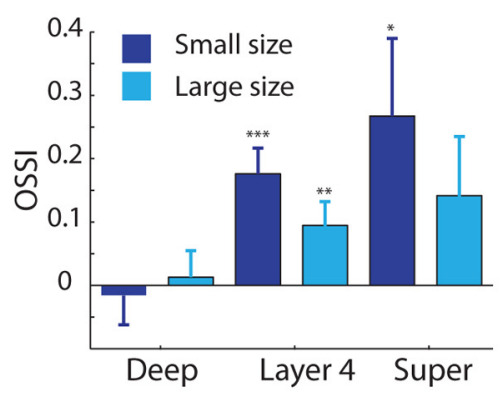

C

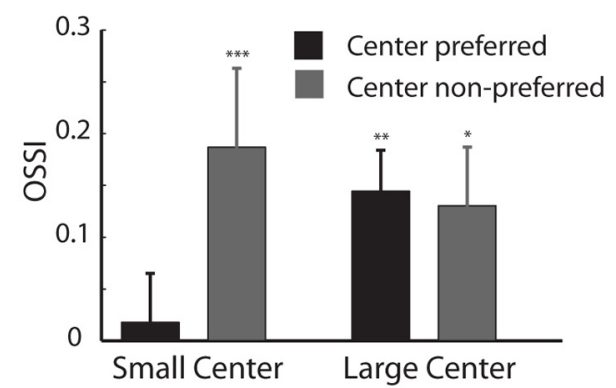

Figure 5. Control analyses for the influence of the surround on the contextual effect. $\boldsymbol{A}$, Activity in the surround-only condition of the $50 \%$ single units that gave the weakest responses to the surround-only stimulus. The data were normalized by subtracting the spontaneous firing rate and dividing by the response to the small size center condition. Error bars are SEM. $\boldsymbol{B}$, The 0 SSI from this subpopulation of cells per laminar compartment and stimulus size. Significant 0 SSI values are marked by the asterisks $\left({ }^{*} p<0.05,{ }^{* *} p<0.01\right.$, ${ }^{* * *} p<0.001$, Wilcoxon signed-rank test); the large size data from the superficial layers showed a strong trend ( $p=0.07$ ). C, OSSI values from a subpopulation of well tuned cells that showed a preference for one of the two center orientations (at least a $25 \%$ difference in response) split according to whether the center was stimulated with the preferred or nonpreferred orientation. Asterisks mark significant 0SSI values (Wilcoxon signed-rank test, as above). Spont, spontaneous.

dependent surround suppression is not caused by the activation of the RF center by the surround stimulus.

\section{Time course and laminar profile of surround suppression as assessed with MUAe}

We next examined the MUAe data to obtain a better estimate of the orientation tuning of surround suppression across the layers of V1. The difference between responses elicited by cross- and iso-oriented surrounds was largest for the small center size in layer 4 and the superficial layers (Fig. $6 A, B$ ). We quantified the difference between the cross- and iso-oriented conditions using the OSSI index (Fig. 6A, bars). OSSI varied significantly across layers for both center sizes (Kruskal-Wallis test, small size: $p<$ $10^{-5}$; large size: $p=0.01$ ). The mean OSSI was notably stronger in layer 4 (small size: $0.12 \pm 0.01($ SEM); large size: $0.06 \pm 0.01$ ) and the superficial layers (small size: $0.15 \pm 0.01$; large size: $0.08 \pm 0.01$ ) than in the deep layers (small size: $0.05 \pm 0.01$; large size: $0.03 \pm 0.01$ ), but orientation-tuned suppression in layer 4 and the superficial layers did not differ significantly at either size ( $U$ test, $p>0.05$ ). The full spatiotemporal profile of surround suppression and orientation-tuned suppression has been illustrated in Figure 6B. For the small-size stimuli surround suppression began in layer 4 and then spread rapidly into the superficial layers and later into the deeper layers. Orientation-tuned suppression was restricted to layer 4 and the superficial layers for small-size stimuli, and with the large size it was more prominent in the superficial layers. To gain insight into the circuitry that is responsible for surround suppression and its orientation dependence, we examined the latency of these suppressive effects. Visual inspection of the average MUAe responses suggested that the initial surround suppression was not tuned for orientation. Figure $7 A$ illustrates the MUAe responses from layer 4 . It can be seen that the first effect of the surround is to suppress neuronal activity in an orientation-independent manner and that the orientationdependent surround effect emerged later. These time courses are remarkably similar to those observed in macaque V1 using similar stimuli (Henry et al., 2013). We estimated the timing of the general and orientation-specific surround effects using a curvefitting procedure (see Materials and Methods; Fig. 7B). We first examined the latency of the visual response in the center-only condition for the small-size stimuli (Fig. $7 B, C$, black lines). As expected, latencies were shortest in layers 4 and $6(\sim 85 \mathrm{~ms})$, thus further supporting the accuracy of our depth assignments. We examined the latency of the general surround suppression effect by estimating the timing of the difference between the centeronly and iso-oriented conditions (Fig. $7 B, C$, blue lines). For the small center stimuli surround suppression started in layer 4 (median latency $=111 \mathrm{~ms}), \sim 25 \mathrm{~ms}$ later than the onset of the visual response (Wilcoxon signed-rank test, $p=0.002$ ). The latency of surround suppression differed significantly across compartments (Kruskal-Wallis test, $p<0.006$ ). It was significantly later in the superficial (median latency $=131 \mathrm{~ms}$ ) and deep layers $(136 \mathrm{~ms})$ than in layer 4 (Wilcoxon signed-rank tests, both $p<0.01$, Bonferroni correction applied) with no significant differences between the superficial and deep layers (Wilcoxon signed-rank test, $p=0.8)$.

We next examined the timing of the orientation-specific surround suppression by calculating the difference in response elicited by the cross- and iso-oriented surround stimuli (Fig. $7 B, C$, red lines). The latency of orientation-specific suppression was on average $147 \mathrm{~ms}$ and did not vary significantly across the laminar compartments (Kruskal-Wallis test, $p>0.5$ ), although it did occur significantly later than general surround suppression in all compartments (Wilcoxon signed-rank tests, all $p<0.05$, Bonferroni correction applied). Thus, for the small center stimuli the initial responses that are driven by the center stimulus are followed by a phase of general surround suppression, which in turn, are followed by an orientation-specific surround effect. The order of events for the large center stimuli differed (Figs. $7 D-F$ ). For these stimuli, general surround suppression and orientationtuned suppression began at the same time, $\sim 135 \mathrm{~ms}$ after stimulus onset, without significant timing differences between laminar compartments (all $p>0.2$ ).

Is the short latency of general suppression at the small size genuinely different from the latency of the other suppressive processes, or is it caused by a faster rate of increase of this suppressive process? To address this question, we analyzed the slopes of the latency fits (see Materials and Methods). We did not observe significant differences between slopes within any compartment (Wilcoxon signed-rank tests, all $p>0.3$ ). These results, taken together, suggest that the mechanisms for early orientationindependent suppression caused by image regions close to the RF differ from the mechanism for orientation-selective suppression and also from the mechanism for suppression by visual information far from the RF. 


\section{Static gratings}

In the experiments described above we presented drifting gratings. A previous study demonstrated retinal circuits that can segregate an object from the background on the basis of a difference in motion direction (Olveczky et al., 2003). We therefore considered the possibility that these retinal circuits contribute to the differences in neuronal activity elicited by the moving cross- and iso-oriented surround stimuli. To estimate the contribution of motion-contrast detection mechanisms to surround suppression in V1 we also examined the MUAe responses to static gratings. The gratings were identical to those used in the above experiments except that they were stationary, while the spatial phase of the grating was randomized across trials. In these experiments, stimulus duration was reduced to $0.5 \mathrm{~s}$.

Figure $8 A$ shows MUAe responses at all the recording sites of a representative penetration. The laminar profile of the response revealed a marked difference in the level of sustained activity between the layers. Sustained activity was considerably higher in layer 5 and the superficial layers whereas responses were more transient in layers 4 and 6 . This pattern of sustained activity closely resembles the pattern of activity elicited with static stimuli across the layers in area V1 of awake macaque monkeys (Self et al., 2013). Just as was observed with moving grating stimuli, surround suppression with static stimuli was strongest if the orientation of the surround matched the orientation of the center stimulus (Fig. $8 A$, compare middle and right graph), regardless of the size of the center stimulus. We obtained similar results across the population of 13 penetrations tested with stationary gratings (Fig. $8 B)$. We quantified the dependence of surround suppression on the orientation of the surround with the OSSI (Fig. $8 C$ ). The OSSI was significantly greater than zero in layer 5, layer 4, and the superficial layers at both center sizes, which indicates that iso-oriented surround stimuli generated strongest suppression (Wilcoxon signed-rank tests, all $p<0.05$ ). We note, however, the differences in OSSI indices between the layers were not significant, at either size of the center stimulus (Kruskal-Wallis test, both $p>0.1)$.

\section{Blocking activity in the superficial layers with lidocaine}

A recent study (Adesnik et al., 2012) proposed a cortical mechanism for surround suppression in which somatostatin (SST)positive interneurons, located in the su-
A

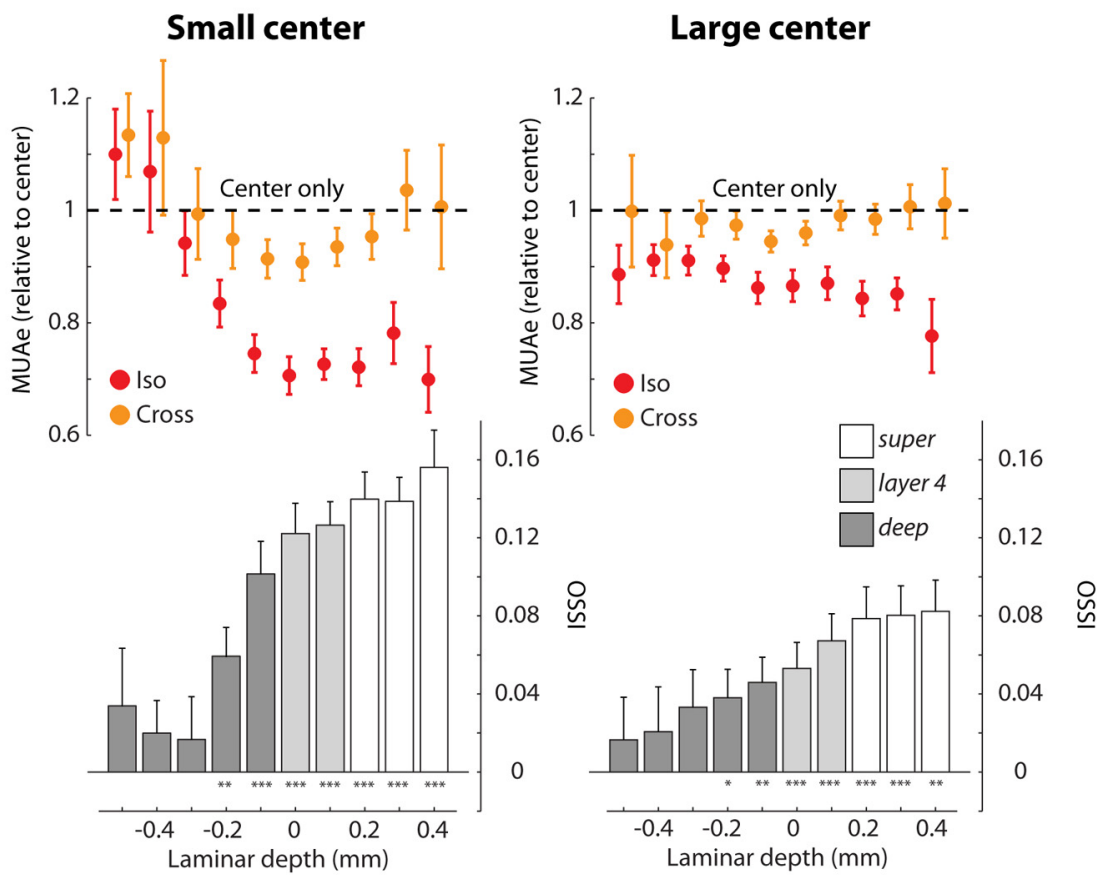

\section{B Small center}
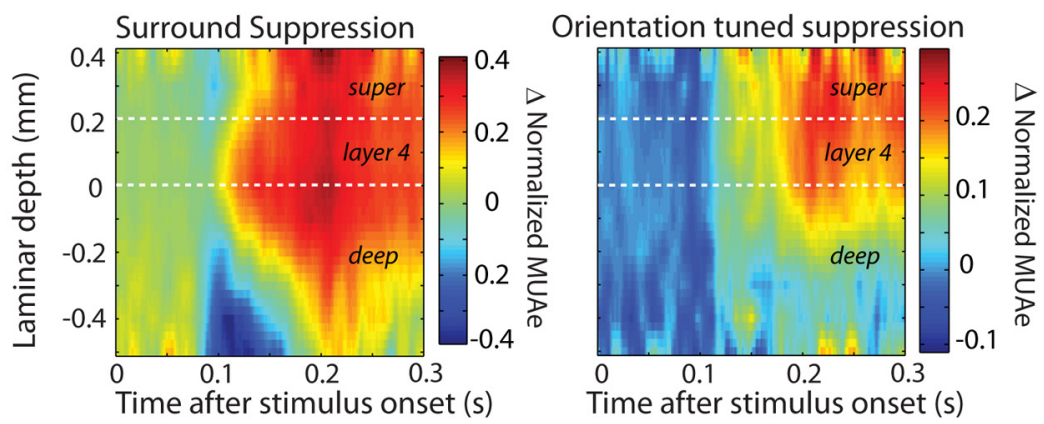

\section{Large center}

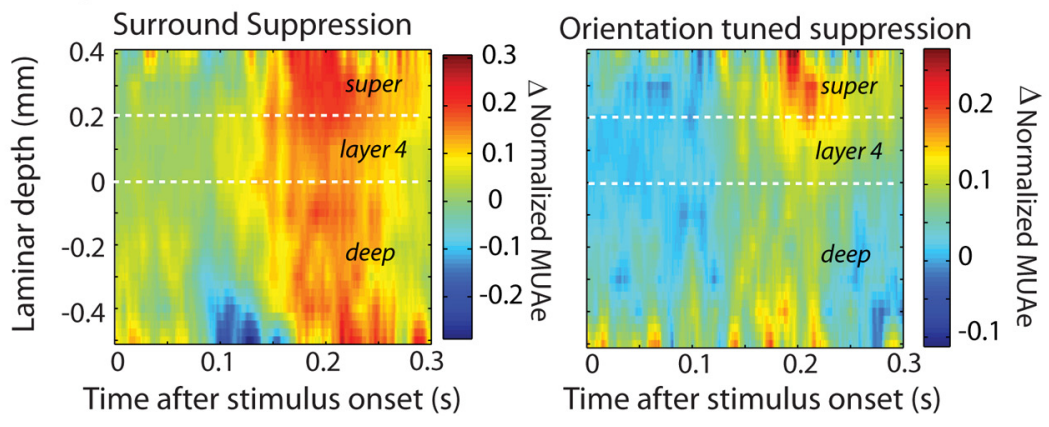

Figure 6. The effect of orientation context on multi-unit responses. $A$, The upper graphs (colored circles) show the difference in MUAe responses relative to the center-only response produced by the addition of an iso-oriented (red dots) or cross-oriented (orange dots) grating at different cortical depths. For each center size the responses were normalized by the center-only responses of the same size. Left (right) illustrates responses elicited by the small (large) center stimulus. Error bars show SEM. The lower bar graphs show the OSSI for each layer. Error bars denote SEM. The asterisks on the $x$-axis indicate the significance of the OSSI (Wilcoxon signed-rank tests: $\left.{ }^{*} p<0.05,{ }^{* *} p<0.01,{ }^{* * *} p<0.001\right) . \boldsymbol{B}$, The spatiotemporal profile of surround suppression. Left, Illustrates general surround suppression as measured by the difference between activity evoked by the small (top) or large center-only stimulus (bottom) and the stimulus with an iso-oriented surround. Depth is indicated on the $y$-axis (deeper channels at the bottom). The response difference was linearly interpolated across layers (spacing of $0.01 \mathrm{~mm}$ ). Red (blue) colors indicate that response was suppressed (facilitated) by the surround. Suppression starts in layer 4 and then spreads toward the superficial layers, but less so into the deep layers. Right, lllustrates the orientation tuning of surround suppression, measured as the difference in activity elicited by cross- and iso-oriented surround stimuli. The relative increase in activity evoked by the cross-oriented surround starts later than the general surround suppression effect and was largely confined to the upper layers. 


\section{Small Center}

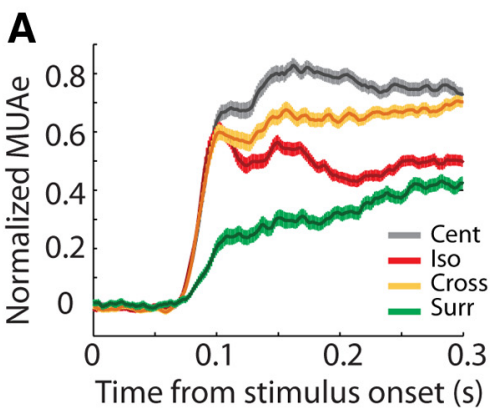

\section{Large Center}

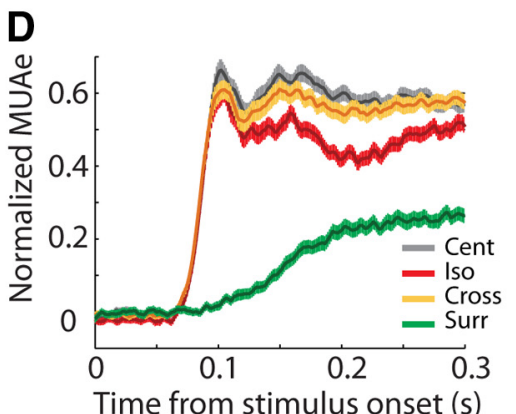

B

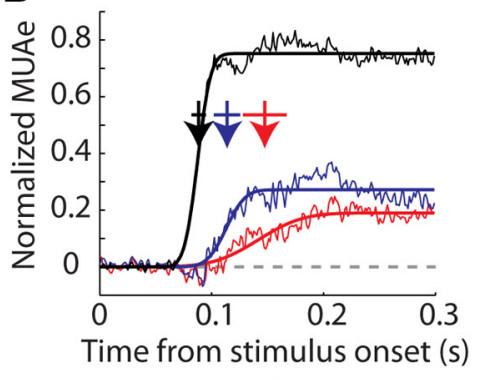

- Cent — Cent - Iso - Cross - Iso

\section{E}

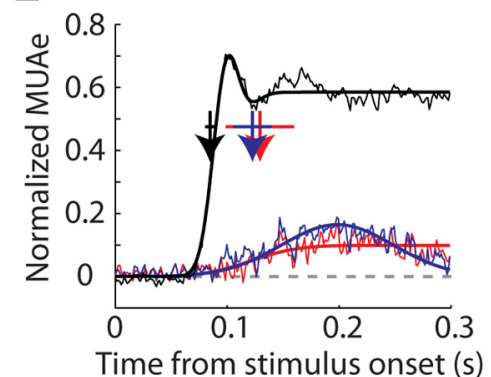

C

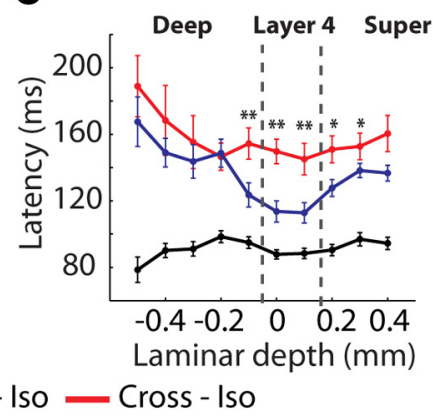

$\mathbf{F}$

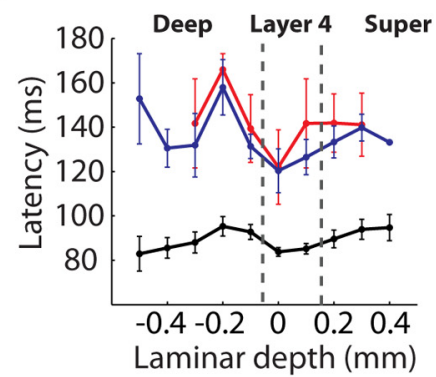

- Cent - Cent - Iso - Cross - Iso

Figure 7. Latency analysis. $\boldsymbol{A}$, The average normalized MUAe response elicited in layer 4 by small center gratings presented in isolation (gray), in combination with the iso-oriented (red) and cross-oriented surround (orange) and the response elicited by the surround-only stimulus (green). The shaded region indicates \pm 1 SEM. $\boldsymbol{B}$, The average visual response (black line), general surround suppression (blue line), and orientation-dependent surround suppression (red line) with the small size center grating in layer $4(z=0 \mathrm{~mm})$. The arrows show the mean latencies of each condition across recording sites as measured with a curve-fitting procedure (see Materials and Methods) and the horizontal bars show $95 \%$ confidence intervals. $C$, The mean latencies across the different laminar depths of the visual response (black), general surround suppression (blue), and orientation-specific surround suppression (red) evoked by small center gratings. Significant differences (Wilcoxon signed-rank tests, $p<0.05$ ) between the latencies of the orientation-selective suppression and general surround suppression are marked with asterisks. Error bars are SEM across penetrations. $\boldsymbol{D}$, The average normalized MUAe response elicited in layer 4 by large center gratings. $\boldsymbol{E}$, The average visual response, tuned and nontuned suppression time courses for the large size center stimuli (conventions as in $\boldsymbol{B}$ ). $\boldsymbol{F}$, The mean latencies for the large-size stimuli (conventions as in $\boldsymbol{C}$ ).

perficial layers of cortex, pool activity from pyramidal cells in neighboring regions of $\mathrm{V} 1$ and then suppress local pyramidal cells. This mechanism could also account for the orientation tuning of the surround that we have described above, because SSTpositive interneurons are orientation selective (Ma et al., 2010). To investigate the contribution of the superficial layers of mouse $V 1$ to surround suppression we inactivated the upper cortical layers by applying lidocaine, a voltage-gated sodium-channel blocker, to the dura mater. Lidocaine can diffuse across the dura mater and block both initiation and propagation of action potentials. Preliminary testing with various concentrations and durations of the application established that the superficial layers were reliably silenced with a lidocaine concentration of $2-4 \mathrm{mg} \cdot \mathrm{ml}^{-1}$ for $30 \mathrm{~s}$, whereas the responses in layer 4 were relatively unaffected. Figure $9 \mathrm{~A}$ shows the activity at an example recording site in the superficial layers and a simultaneously recorded site in layer 4 to the same drifting grating stimuli that we used to test the orientation tuning of the surround. Lidocaine caused a rapid reduction of spiking activity at the superficial layer site $(82 \%$ reduction in firing rate) while activity in layer 4 was much less affected ( $23 \%$ reduction in firing rate), although both effects were significant $(t$ test, both $p<0.001)$. We examined the average responses of these sites to the different grating conditions (Fig. 9B). Lidocaine strongly reduced the neuronal responses at the superficial site regardless of the experimental condition. Interestingly, however, the effect of the drug on activity at the layer 4 site was small. Lidocaine caused a small reduction in the visual response, but general surround suppression and the orientation-tuned effect remained similar despite the near complete silencing of the site in the superficial layers.

We examined the effect of lidocaine in a total of nine penetrations with 21 drug applications (Fig. 9C). We restricted our analysis to the subset of applications in which the drug was effective, in that it reduced responses in the superficial layers by at least $33 \%$ (mean reduction $=69.0 \%$ ), while it did not penetrate too deeply, so that responses in layer 4 were decreased by $<33 \%$ (mean $=7.5 \%$ ). Figure $9 D$ illustrates the average effect of lidocaine on the visual response in the different layers for this subset of drug applications. The main effect of lidocaine on visual responsiveness was strongest in the superficial layers (Fig. $9 D$, red line), but there was also a moderate effect in upper layer 4 (depth $=0.1 \mathrm{~mm})$. In contrast, activity in the deep layers and lower layer 4 were not significantly reduced (Fig. 9D, red line). We focused our analysis on neuronal activity in lower layer 4 where surround suppression was pronounced (depth $=0 \mathrm{~mm}$ ). We found no significant effect of lidocaine application on the neural response differences before and after lidocaine application between the center, iso-surround, and cross-surround conditions (Fig. 9E: repeated-measures ANOVAs, small: $F_{(2,26)}=1.6, p=0.22$; large: $\left.F_{(2,26)}>1\right)$.

We next examined the effect of silencing the superficial layers on general surround suppression as well as orientation-selective surround suppression. As a measure for general surround suppression we used the $\mathrm{SI}_{\text {Centsurr }}$ index, which equals the difference in responses elicited by the small center grating and the same 
A

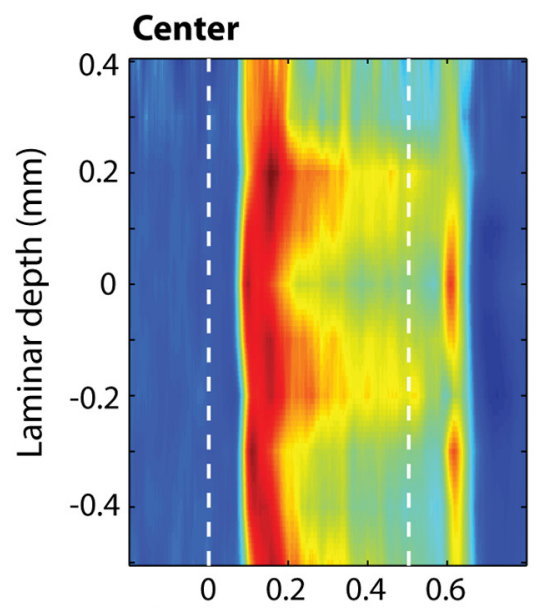

Time after stimulus onset (s)

\section{Static gratings}

Iso

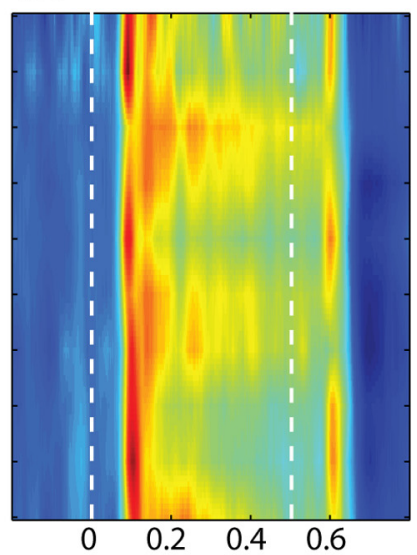
s)
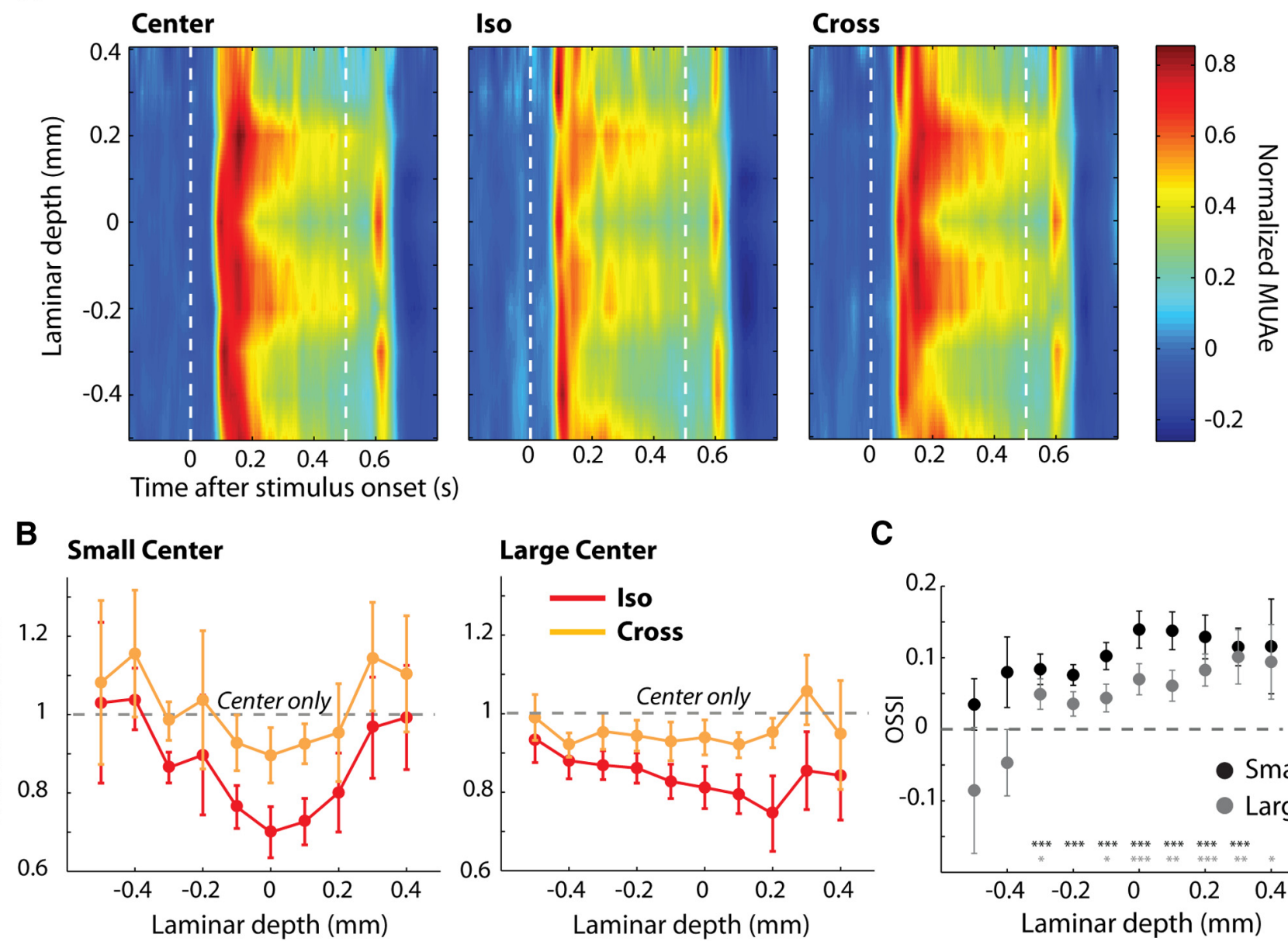

C

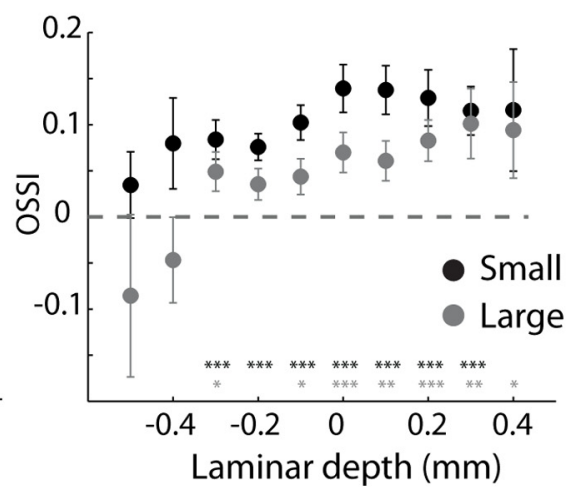

Figure 8. Neuronal responses elicited by static gratings. $\boldsymbol{A}$, Spatiotemporal profiles of MUAe activity from an example penetration in response to static gratings (small center size) presented in isolation (left) or with an iso-oriented (center) or cross-oriented surround (right). The white dashed lines mark the onset and offset of the grating. Bands of higher levels of sustained activity are present in layers 5 and 2/3. Also note the laminar profile of the offset response, which was most pronounced in layers 4 and $6 . \boldsymbol{B}$, The average MUAe responses across all penetrations in which we measured the responses to static gratings $(n=13)$. The data were normalized to the response in the center-only condition (gray dashed line) independently for each center size. $C$, The laminar profile of the 0SSI for small (black) and large (gray) center gratings. Asterisks mark layers for which the OSSI was significantly greater than zero (Wilcoxon signed-rank tests, ${ }^{*} p<0.05,{ }^{* *} p<0.01,{ }^{* * *} p<$ $0.001)$.

grating with the iso-oriented surround, normalized to the sum of these responses (in these experiments we did not have sufficient time to measure the full size-tuning curve; see Materials and Methods). In the presence of lidocaine the average $\mathrm{SI}_{\text {CentSurr }}$ was 0.26 , which was significantly larger than zero ( $t$ test, $p<0.001$ ) but did not differ significantly from the $\mathrm{SI}_{\text {CentSurr }}$ of 0.27 in the predrug epoch ( $t$ test, $p=0.7$ ). We obtained a similar null result for the orientation-selective surround suppression. In the presence of lidocaine the mean OSSI for the small center size was 0.18 (large size $=0.08)$, which was larger than zero ( $t$ test, both sizes $p<0.001$ ) and did not differ from the OSSI of 0.20 (large size $=$ 0.08 ) in the episode before lidocaine was applied (Fig. $9 F ; t$ test, $p>0.3$ for both center sizes). We therefore conclude that an average reduction in the firing rate in the superficial layers by $\sim 70 \%$ neither affects general surround suppression nor the orientation-specific component in layer 4 .

We considered the possibility that the remaining $\sim 30 \%$ of activity in the superficial layers sufficed to produce surround suppression. We therefore examined the neuronal activity in a subset of applications (Fig. 9C, blue and red dots) in which the suppression in the superficial layers was strongest ( $n=6$ pene- trations; mean reduction $=91 \%$ ). In this subset of penetrations, we did not obtain a significant effect of drug application on the $\mathrm{SI}_{\text {CentSurr }}$ or OSSI indices in layer 4 either. The mean $\mathrm{SI}_{\text {CentSurr }}$ changed from 0.19 to 0.24 ( $t$ test, $p=0.18$ ) whereas the OSSI changed from 0.18 to 0.20 (small size) and 0.10 to 0.08 (large size; $t$ test, both $p>0.5$ ). Lidocaine blocks the activity of neurons with cell bodies in the superficial layers and also the corticocortical connections that are present in these layers. These results therefore imply that neuronal activity in the superficial layers as well as connections targeting the superficial layers are not necessary for the generation of surround suppression or the orientationdependent contextual effects in layer 4 of mouse V1.

\section{Discussion}

In this study we have demonstrated that the strength of surround suppression in mouse V1 depends on the orientation of the surround relative to the center. Iso-oriented surrounds produced more suppression than cross-oriented surrounds leading to a relative enhancement of cortical responses to cross-oriented stimuli. This finding of orientation-tuned surrounds is reassuring for studies that use the mouse as a model system for visual process- 
A
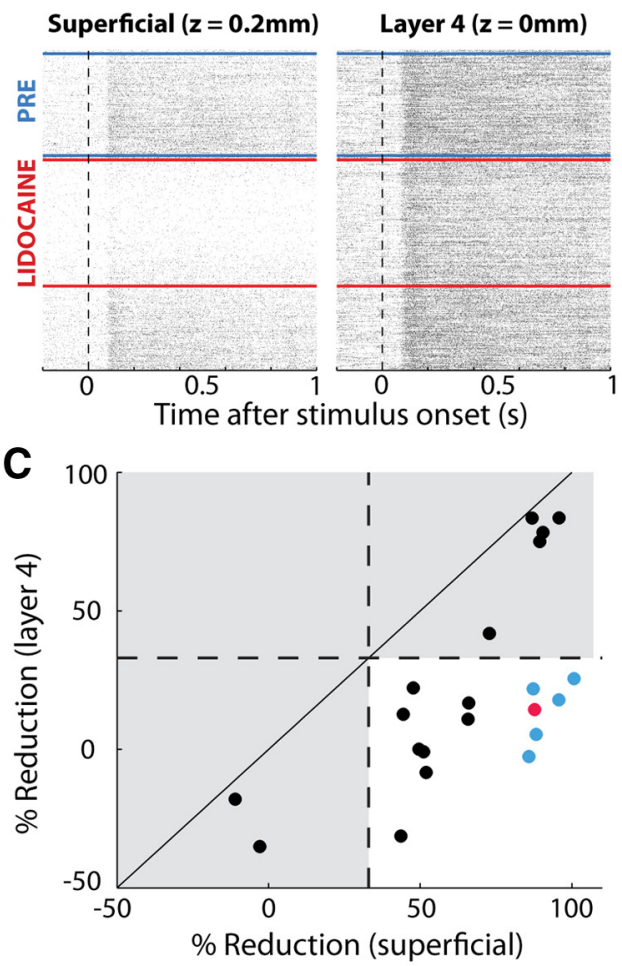

E

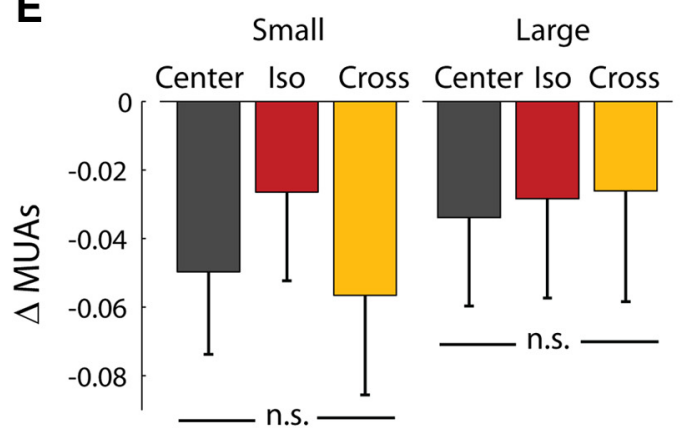

B

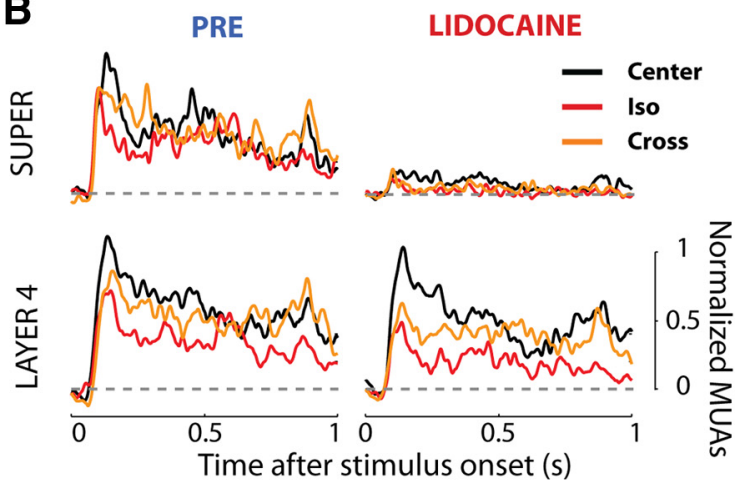

D

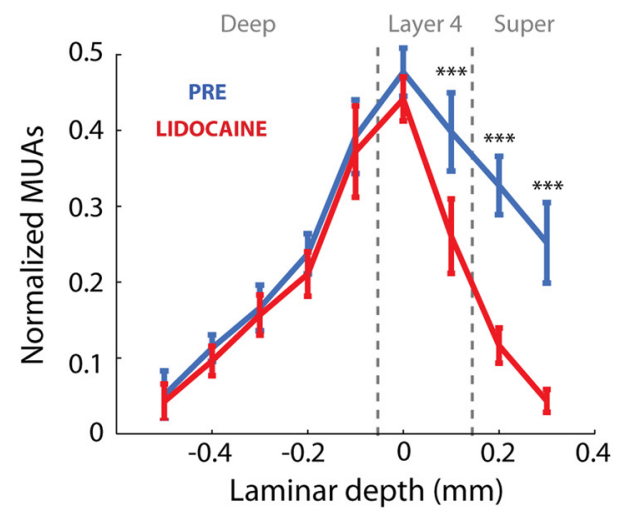

$\mathbf{F}$

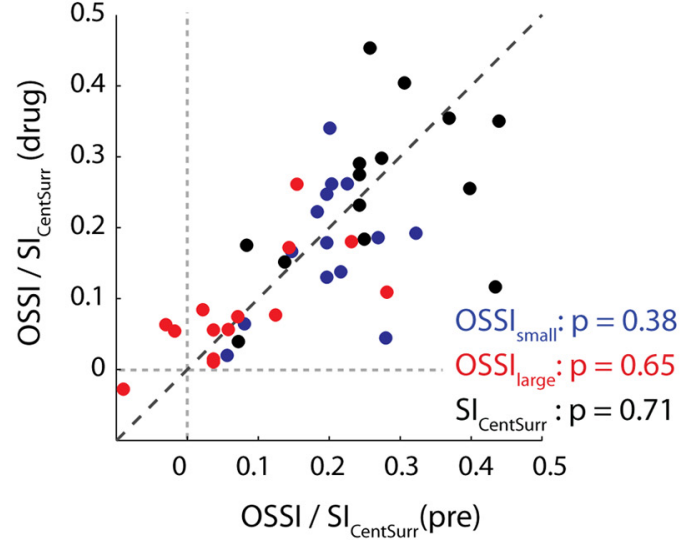

Figure 9. The effect of lidocaine on surround suppression. $\boldsymbol{A}$, We topically applied lidocaine to the dural surface to block activity in the superficial layers. The raster plots show MUAs from a superficial layer site (left) and a simultaneously recorded site in layer 4 (right) during successive presentations of drifting gratings ( 904 trials, only those trials in which the center was stimulated are shown). The blue lines mark the predrug period. Lidocaine was applied for $30 \mathrm{~s}$ at the time marked by the uppermost red line. Lidocaine caused a rapid reduction of background spiking activity in the superficial site and the visually evoked response. The effect of the drug lasted $\sim 9$ min as estimated by the time at which response amplitude had resumed to $75 \%$ of the predrug level (marked by the second red line). Responsiveness in layer 4 (right) was not strongly affected by the lidocaine application. $\boldsymbol{B}$, The average responses to drifting gratings at the two recording sites of $\boldsymbol{A}$. Lidocaine almost completely abolished visual responses at the superficial layer site (top row), whereas responses elicited in layer 4 were only slightly reduced. Note that the orientation-tuned surround suppression in layer 4 persists after the application of the drug. $\boldsymbol{C}$, Inclusion criteria were based on the percentage change in spiking activity caused by lidocaine. Positive numbers indicate that the drug reduced the response and we only included penetrations in which the reduction in superficial layers was at least $33 \%$ while the reduction in layer 4 was $<33 \%$ in our analysis (white region). The red dot indicates the penetration illustrated in $\boldsymbol{A}$ and $\boldsymbol{B}$. We obtained similar results when we limited our analysis to the penetrations indicated in blue (and red), which exhibited a near complete silencing of the superficial layers. $\boldsymbol{D}$, The mean visually evoked MUA response across the included penetrations elicited by the center-only stimulus before (blue) and after application of lidocaine (red). The drug only significantly reduced responses in the superficial layers and upper layer 4 . We limited our analysis to recording sites at a depth of $0 \mathrm{~mm}$ (lower layer 4 ) to avoid direct effects of the drug. $\boldsymbol{E}$, The change in MUA response induced by the drug in lower layer 4 . Lidocaine reduced responses in all conditions by a small amount and there were no significant differences between the different conditions. $\boldsymbol{F}$, Scatter plot showing the OSSI (red and blue dots) and SI ${ }_{\text {CentSurr }}$ (black dots) in lower layer 4 in the predrug ( $x$-axis) and postdrug ( $y$-axis) period. We observed no significant change in $\mathrm{SI}_{\text {CentSurr }}$ or OSSI.

ing. The lack of orientation columns in rodent visual cortex (Van Hooser et al., 2005; Ohki and Reid, 2007) raised the question of whether orientation-specific contextual effects exist in these animals. Our results demonstrate that a columnar organization is not essential for the orientation-dependent contextual effects in visual cortex. In accordance with previous studies (Adesnik et al.,
2012; Haider et al., 2013), we found that the strength of surround suppression depends on the depth of anesthesia, with stronger suppression in lighter states of anesthesia. Furthermore, we found that the orientation dependence of surround suppression also occurs with stationary stimuli, which implies that it does not depend on retinal mechanisms that detect motion contrast 
(Olveczky et al., 2003). Finally, we found that surround suppression as well as its orientation dependence remains if the superficial layers of $\mathrm{V} 1$ are inactivated.

\section{The timing and laminar profile of orientation-dependent surround suppression in mice and primates}

We observed three phases in the neuronal responses elicited by the visual stimuli in V1. The initial neuronal responses with a latency of $\sim 85 \mathrm{~ms}$ were little influenced by context. This was followed by a phase of general surround suppression, which started in layer 4 with a latency of $\sim 110 \mathrm{~ms}$ for small-sized stimuli. The third phase was characterized by orientation-dependent surround suppression, which occurred at $\sim 135-150 \mathrm{~ms}$ after stimulus onset and began at a similar time point across all layers. There appears to be a difference between suppression coming from the immediate surround of the RF and suppression coming from further away. When we used small-sized center stimuli we observed a rapid nontuned suppression that was not present when we used larger stimuli. Notably, when using the large size center stimuli the appearance of tuned suppression was simultaneous with the appearance of general surround suppression. These findings are reminiscent of findings in macaque V1 (Bair et al., 2003; Webb et al., 2005; Xing et al., 2005; Henry et al., 2013). For example Henry et al. (2013) recently found that orientationtuned suppression from outside the classical RF lags nontuned suppression by $\sim 25 \mathrm{~ms}$.

In our study the small stimulus size was chosen based on the peak of the size-tuning curve in layer 4 , which is a common measure of RF size (Angelucci and Bullier, 2003). However, as the preferred size varied across layers we could not choose a small stimulus size that was completely outside the RF for all cells in the penetration. We therefore considered the possibility that mechanisms within the classical RF contributed to the suppression (DeAngelis et al., 1992). However we found that nontuned suppression first arose in layer 4 where RFs were smallest (Figs. 2, $3 F)$. Furthermore, suppression from within the RF has been shown to be extremely rapid, arriving at a similar time point, or even earlier, than the visual response (Priebe and Ferster, 2006; Smith et al., 2006) whereas the nontuned suppression observed in this study arrived with a clear delay. Thus, the general surround suppression studied here is a contextual effect and differs from the suppressive mechanisms that operate within the RF.

We observed large differences in the strength of surround suppression across layers. Surround suppression was strong in layer 4 and the superficial layers and we generally observed few differences between these two laminar compartments. In contrast, suppression was weaker or absent in the deep layers. These results concur with a recent study in sedated animals (Nienborg et al., 2013) and another study in awake animals (Vaiceliunaite et al., 2013), although a third study in anesthetized animals did not find clear laminar differences (Van den Bergh et al., 2010).

It is of interest to compare the present laminar profile of contextual modulation with the profile observed in primates. In the monkey, surround suppression is weakest in the deep layers of $\mathrm{V} 1$ and stronger in the superficial layers (Sceniak et al., 2001; Levitt and Lund, 2002; Henry et al., 2013), just as observed by us in the mouse. There are some differences between primate studies in the amount of suppression that has been reported for layer 4 . Sceniak et al. (2001) and Henry et al. (2013) found strong suppression in layer $4 \mathrm{~B}$ and weaker suppression in layer $4 \mathrm{C}$ (but see Shushruth et al., 2009,2013 who found relatively strong suppression in layer $4 \mathrm{C} \alpha$ ). Overall, surround suppression in the mouse appears to be weaker than that in the monkey (Henry et al., 2013). Further- more, it is difficult to directly compare layer 4 in mouse to monkey with its more intricate structure. Yet, it is of interest that suppression in input layer 4 in the mouse is comparatively strong, whereas it is relatively weak in input layer $4 \mathrm{C}$ in the monkey, compared with the other layers (Henry et al., 2013).

\section{Contributions from subcortical structures to surround suppression}

In primates and cats there are strong suppressive surround effects in the LGN (Jones et al., 2000; Solomon et al., 2002; Bonin et al., 2005; Sceniak et al., 2006; Alitto and Usrey, 2008). Thus, V1 surround suppression might be inherited, in part, from the LGN. Our finding that general surround suppression begins in layer 4 is consistent with such a subcortical origin. However, suppression was delayed by $\sim 25 \mathrm{~ms}$ relative to the visual response, which implies that the initial input into layer 4 is not susceptible to surround suppression (Knierim and van Essen, 1992;Nothdurft et al., 1999;Bair et al., 2003; Vaiceliunaite et al., 2013). In contrast, Alitto and Usrey (2008) demonstrated that suppression in monkey LGN is present from the start of the visual response. Furthermore suppressive surrounds in the LGN are too small to account for the spatial extent of cortical surround suppression (Jones et al., 2002; Ozeki et al., 2009), and the surrounds in the LGN are only weakly tuned to orientation (Sillito et al., 1993; Solomon et al., 2002; Bonin et al., 2005; Ozeki et al., 2009). These results suggest that the delayed suppression in cats and monkeys is not inherited from the LGN. In the mouse the situation is different, because orientation tuning in the LGN is stronger than that in cats and monkeys (Marshel et al., 2012; Piscopo et al., 2013; Scholl et al., 2013), albeit weaker than that in mouse V1. We can therefore not entirely rule out a possible contribution of orientationtuned LGN cells to surround suppression in V1 of mice, although this process would have to develop slowly to account for the delay in V1 surround suppression relative to the visual response. Such an LGN contribution could rely on corticothalamic interactions involving the layer 6 cells that project back to the LGN and control the gain of relay cells that provide the input to layer 4 of V1 (Sillito et al., 1993).

\section{The cortical circuits that generate surround suppression}

If cortical circuits do contribute to the generation of orientationdependent surround suppression, then what is the mechanism? A recent study (Adesnik et al., 2012) demonstrated that SSTpositive interneurons contribute to surround suppression in the superficial layers of mouse visual cortex. We tested the involvement of the superficial layers and, indirectly, the SST interneurons in these layers by applying lidocaine to the dura mater. Silencing of the superficial layers as well as the horizontal and feedback connections that target layers 1-3 had only a small influence on responses in the deep layers or in layer 4. This may seem surprising as the standard model of the cortical microcircuit holds that deep layers receive the majority of their intracortical input from the superficial layers (Douglas and Martin, 2004), but supports recent findings that neurons in layers 5 and 6 receive most of their visual drive directly from the thalamus (Constantinople and Bruno, 2013). We found that silencing of the superficial layers did not influence general surround suppression or orientation-tuned surround suppression in layer 4 . These results do not rule out the possibility that SST cells in the superficial layers contribute to surround suppression in these layers, or that SST cells in other layers contribute to the suppression in layer 4 . Nevertheless, our findings demonstrate that surround suppression in layer 4 is not inherited from the superficial layers via the 
cortical microcircuitry. Because surround suppression in layer 4 is not computed in the superficial layers, we have to consider other sources for these suppressive surround effects. Apart from the possible contribution from the LGN discussed above, a further possibility is that surround suppression is generated de novo in layer 4. Indeed, it is conceivable that horizontal interactions that involve interneurons in layer 4 and the deep layers are responsible for surround suppression in this layer. A recent study demonstrated that the activation of SST interneurons indeed increases surround suppression in deeper layers (Nienborg et al., 2013), although the effect on layer 4 neurons was limited. A second possible cortical origin for surround suppression is feedback from higher visual areas. Although these connections target layer 1 , which was silenced in our experiments, they also make contacts in layer 5 (Domenici et al., 1995) and thereby route information about the stimulus context back to V1 (Angelucci et al., 2002; Bair et al., 2003; Angelucci and Bressloff, 2006). The role of feedback in surround suppression is supported by a recent study, which demonstrated that cooling of areas V2 and V3 in monkeys decreases surround suppression in V1 (Nassi et al., 2013).

\section{Conclusion}

We conclude that cells in mouse primary visual cortex are suppressed in an orientation-tuned fashion by surrounding stimuli. The laminar and temporal profile of orientation-tuned surround suppression in mouse $\mathrm{V} 1$ raises the possibility of two separate cortical mechanisms. The first is a rapid process that rapidly suppresses neuronal activity in layer 4 and the superficial layers for stimuli that extend beyond the classical RF regardless of their orientation. The second is a slower, orientation-tuned mechanism, which results in a relative enhancement for orientations that differ from the background. Future experiments that alter neural activity in V1 or in higher areas can now exploit these findings to further elucidate the mechanisms for orientationtuned surround suppression in visual cortex.

\section{References}

Adesnik H, Bruns W, Taniguchi H, Huang ZJ, Scanziani M (2012) A neural circuit for spatial summation in visual cortex. Nature 490:226-231. CrossRef Medline

Alitto HJ, Usrey WM (2008) Origin and dynamics of extraclassical suppression in the lateral geniculate nucleus of the macaque monkey. Neuron 57:135-146. CrossRef Medline

Angelucci A, Bressloff PC (2006) Contribution of feedforward, lateral and feedback connections to the classical receptive field center and extraclassical receptive field surround of primate V1 neurons. Prog Brain Res 154:93-120. CrossRef Medline

Angelucci A, Bullier J (2003) Reaching beyond the classical receptive field of V1 neurons: horizontal or feedback axons? J Physiol Paris 97:141-154. CrossRef Medline

Angelucci A, Levitt JB, Lund JS (2002) Anatomical origins of the classical receptive field and modulatory surround field of single neurons in macaque visual cortical area V1. Prog Brain Res 136:373-388. CrossRef Medline

Bair W, Cavanaugh JR, Movshon JA (2003) Time course and time-distance relationships for surround suppression in macaque V1 neurons. J Neurosci 23:7690-7701. Medline

Bonin V, Mante V, Carandini M (2005) The suppressive field of neurons in lateral geniculate nucleus. J Neurosci 25:10844-10856. CrossRef Medline

Cannon MW, Fullenkamp SC (1991) Spatial interactions in apparent contrast: inhibitory effects among grating patterns of different spatial frequencies, spatial positions and orientations. Vision Res 31:1985-1998. CrossRef Medline

Cavanaugh JR, Bair W, Movshon JA (2002) Nature and interaction of signals from the receptive field center and surround in macaque V1 neurons. J Neurophysiol 88:2530-2546. CrossRef Medline
Constantinople CM, Bruno RM (2013) Deep cortical layers are activated directly by thalamus. Science 340:1591-1594. CrossRef Medline

DeAngelis GC, Robson JG, Ohzawa I, Freeman RD (1992) Organization of suppression in receptive fields of neurons in cat visual cortex. J Neurophysiol 68:144-163. Medline

Domenici L, Harding GW, Burkhalter A (1995) Patterns of synaptic activity in forward and feedback pathways within rat visual cortex. J Neurophysiol 74:2649-2664. Medline

Douglas RJ, Martin KA (2004) Neuronal circuits of the neocortex. Annu Rev Neurosci 27:419-451. CrossRef Medline

Haider B, Haüsser M, Carandini M (2013) Inhibition dominates sensory responses in the awake cortex. Nature 493:97-100. CrossRef Medline

Henry CA, Joshi S, Xing D, Shapley RM, Hawken MJ (2013) Functional characterization of the extraclassical receptive field in macaque v1: contrast, orientation, and temporal dynamics. J Neurosci 33:6230-6242. CrossRef Medline

Jones HE, Andolina IM, Oakely NM, Murphy PC, Sillito AM (2000) Spatial summation in lateral geniculate nucleus and visual cortex. Exp Brain Res 135:279-284. CrossRef Medline

Jones HE, Grieve KL, Wang W, Sillito AM (2001) Surround suppression in primate V1. J Neurophysiol 86:2011-2028. Medline

Jones HE, Wang W, Sillito AM (2002) Spatial organization and magnitude of orientation contrast interactions in primate V1. J Neurophysiol 88: 2796-2808. CrossRef Medline

Joseph JS, Optican LM (1996) Involuntary attentional shifts due to orientation differences. Percept Psychophys 58:651-665. CrossRef Medline

Knierim JJ, van Essen DC (1992) Neuronal responses to static texture patterns in area V1 of the alert macaque monkey. J Neurophysiol 67:961-980. Medline

Lamme VA (1995) The neurophysiology of figure-ground segregation in primary visual cortex. J Neurosci 15:1605-1615. Medline

Levitt JB, Lund JS (1997) Contrast dependence of contextual effects in primate visual cortex. Nature 387:73-76. CrossRef Medline

Levitt JB, Lund JS (2002) The spatial extent over which neurons in macaque striate cortex pool visual signals. Vis Neurosci 19:439-452. Medline

Li W, Thier P, Wehrhahn C (2001) Neuronal responses from beyond the classic receptive field in V1 of alert monkeys. Exp Brain Res 139:359-371. CrossRef Medline

Logothetis NK, Kayser C, Oeltermann A (2007) In vivo measurement of cortical impedance spectrum in monkeys: implications for signal propagation. Neuron 55:809-823. CrossRef Medline

Ma WP, Liu BH, Li YT, Huang ZJ, Zhang LI, Tao HW (2010) Visual representations by cortical somatostatin inhibitory neurons-selective but with weak and delayed responses. J Neurosci 30:14371-14379. CrossRef Medline

Marshel JH, Kaye AP, Nauhaus I, Callaway EM (2012) Anterior-posterior direction opponency in the superficial mouse lateral geniculate nucleus. Neuron 76:713-720. CrossRef Medline

Mitzdorf U (1985) Current source-density method and application in cat cerebral cortex: investigation of evoked potentials and EEG phenomena. Physiol Rev 65:37-100. Medline

Nassi JJ, Lomber SG, Born RT (2013) Corticocortical feedback contributes to surround suppression in $\mathrm{vl}$ of the alert primate. J Neurosci 33:85048517. CrossRef Medline

Nelson JI, Frost BJ (1978) Orientation-selective inhibition from beyond the classic visual receptive field. Brain Res 139:359-365. CrossRef Medline

Niell CM, Stryker MP (2008) Highly selective receptive fields in mouse visual cortex. J Neurosci 28:7520-7536. CrossRef Medline

Nienborg H, Hasenstaub A, Nauhaus I, Taniguchi H, Huang ZJ, Callaway EM (2013) Contrast dependence and differential contributions from somatostatin- and parvalbumin-expressing neurons to spatial integration in mouse v1. J Neurosci 33:11145-11154. CrossRef Medline

Nothdurft HC, Gallant JL, Van Essen DC (1999) Response modulation by texture surround in primate area V1: correlates of "popout" under anesthesia. Vis Neurosci 16:15-34. Medline

Ohki K, Reid RC (2007) Specificity and randomness in the visual cortex. Curr Opin Neurobiol 17:401-407. CrossRef Medline

Ohki K, Chung S, Ch'ng YH, Kara P, Reid RC (2005) Functional imaging with cellular resolution reveals precise micro-architecture in visual cortex. Nature 433:597-603. CrossRef Medline

Olveczky BP, Baccus SA, Meister M (2003) Segregation of object and background motion in the retina. Nature 423:401-408. CrossRef Medline 
Ozeki H, Finn IM, Schaffer ES, Miller KD, Ferster D (2009) Inhibitory stabilization of the cortical network underlies visual surround suppression. Neuron 62:578-592. CrossRef Medline

Piscopo DM, El-Danaf RN, Huberman AD, Niell CM (2013) Diverse visual features encoded in mouse lateral geniculate nucleus. J Neurosci 33:46424656. CrossRef Medline

Pooresmaeili A, Herrero JL, Self MW, Roelfsema PR, Thiele A (2010) Suppressive lateral interactions at parafoveal representations in primary visual cortex. J Neurosci 30:12745-12758. CrossRef Medline

Priebe NJ, Ferster D (2006) Mechanisms underlying cross-orientation suppression in cat visual cortex. Nat Neurosci 9:552-561. CrossRef Medline

Quiroga RQ, Nadasdy Z, Ben-Shaul Y (2004) Unsupervised spike detection and sorting with wavelets and superparamagnetic clustering. Neural Comput 16:1661-1687. CrossRef Medline

Sceniak MP, Hawken MJ, Shapley R (2001) Visual spatial characterization of macaque V1 neurons. J Neurophysiol 85:1873-1887. Medline

Sceniak MP, Chatterjee S, Callaway EM (2006) Visual spatial summation in macaque geniculocortical afferents. J Neurophysiol 96:3474-3484. CrossRef Medline

Scholl B, Tan AY, Corey J, Priebe NJ (2013) Emergence of orientation selectivity in the Mammalian visual pathway. J Neurosci 33:10616-10624. CrossRef Medline

Schwabe L, Ichida JM, Shushruth S, Mangapathy P, Angelucci A (2010) Contrast-dependence of surround suppression in Macaque V1: experimental testing of a recurrent network model. Neuroimage 52:777-792. CrossRef Medline

Self MW, Kooijmans RN, Supèr H, Lamme VA, Roelfsema PR (2012) Different glutamate receptors convey feedforward and recurrent processing in macaque V1. Proc Natl Acad Sci U S A 109:11031-11036. CrossRef Medline

Self MW, van Kerkoerle T, Supèr H, Roelfsema PR (2013) Distinct roles of the cortical layers of area V1 in figure-ground segregation. Curr Biol 23:2121-2129. CrossRef Medline

Shushruth S, Ichida JM, Levitt JB, Angelucci A (2009) Comparison of spatial summation properties of neurons in macaque V1 and V2. J Neurophysiol 102:2069-2083. CrossRef Medline

Shushruth S, Mangapathy P, Ichida JM, Bressloff PC, Schwabe L, Angelucci A
(2012) Strong recurrent networks compute the orientation tuning of surround modulation in the primate primary visual cortex. J Neurosci 32:308-321. CrossRef Medline

Shushruth S, Nurminen L, Bijanzadeh M, Ichida JM, Vanni S, Angelucci A (2013) Different orientation tuning of near- and far-surround suppression in macaque primary visual cortex mirrors their tuning in human perception. J Neurosci 33:106-119. CrossRef Medline

Sillito AM, Cudeiro J, Murphy PC (1993) Orientation sensitive elements in the corticofugal influence on centre-surround interactions in the dorsal lateral geniculate nucleus. Exp Brain Res 93:6-16. Medline

Sillito AM, Grieve KL, Jones HE, Cudeiro J, Davis J (1995) Visual cortical mechanisms detecting focal orientation discontinuities. Nature 378:492496. CrossRef Medline

Smith MA, Bair W, Movshon JA (2006) Dynamics of suppression in macaque primary visual cortex. J Neurosci 26:4826-4834. CrossRef Medline

Solomon SG, White AJ, Martin PR (2002) Extraclassical receptive field properties of parvocellular, magnocellular, and koniocellular cells in the primate lateral geniculate nucleus. J Neurosci 22:338-349. Medline

Supèr H, Roelfsema PR (2005) Chronic multiunit recordings in behaving animals: advantages and limitations. Prog Brain Res 147:263-282. CrossRef Medline

Vaiceliunaite A, Erisken S, Franzen F, Katzner S, Busse L (2013) Spatial integration in mouse primary visual cortex. J Neurophysiol 110:964-972. CrossRef Medline

Van den Bergh G, Zhang B, Arckens L, Chino YM (2010) Receptive-field properties of $\mathrm{V} 1$ and $\mathrm{V} 2$ neurons in mice and macaque monkeys. J Comp Neurol 518:2051-2070. CrossRef Medline

Van Hooser SD, Heimel JA, Chung S, Nelson SB, Toth LJ (2005) Orientation selectivity without orientation maps in visual cortex of a highly visual mammal. J Neurosci 25:19-28. CrossRef Medline

Webb BS, Dhruv NT, Solomon SG, Tailby C, Lennie P (2005) Early and late mechanisms of surround suppression in striate cortex of macaque. J Neurosci 25:11666-11675. CrossRef Medline

Xing D, Shapley RM, Hawken MJ, Ringach DL (2005) Effect of stimulus size on the dynamics of orientation selectivity in Macaque V1. J Neurophysiol 94:799-812. CrossRef Medline 